
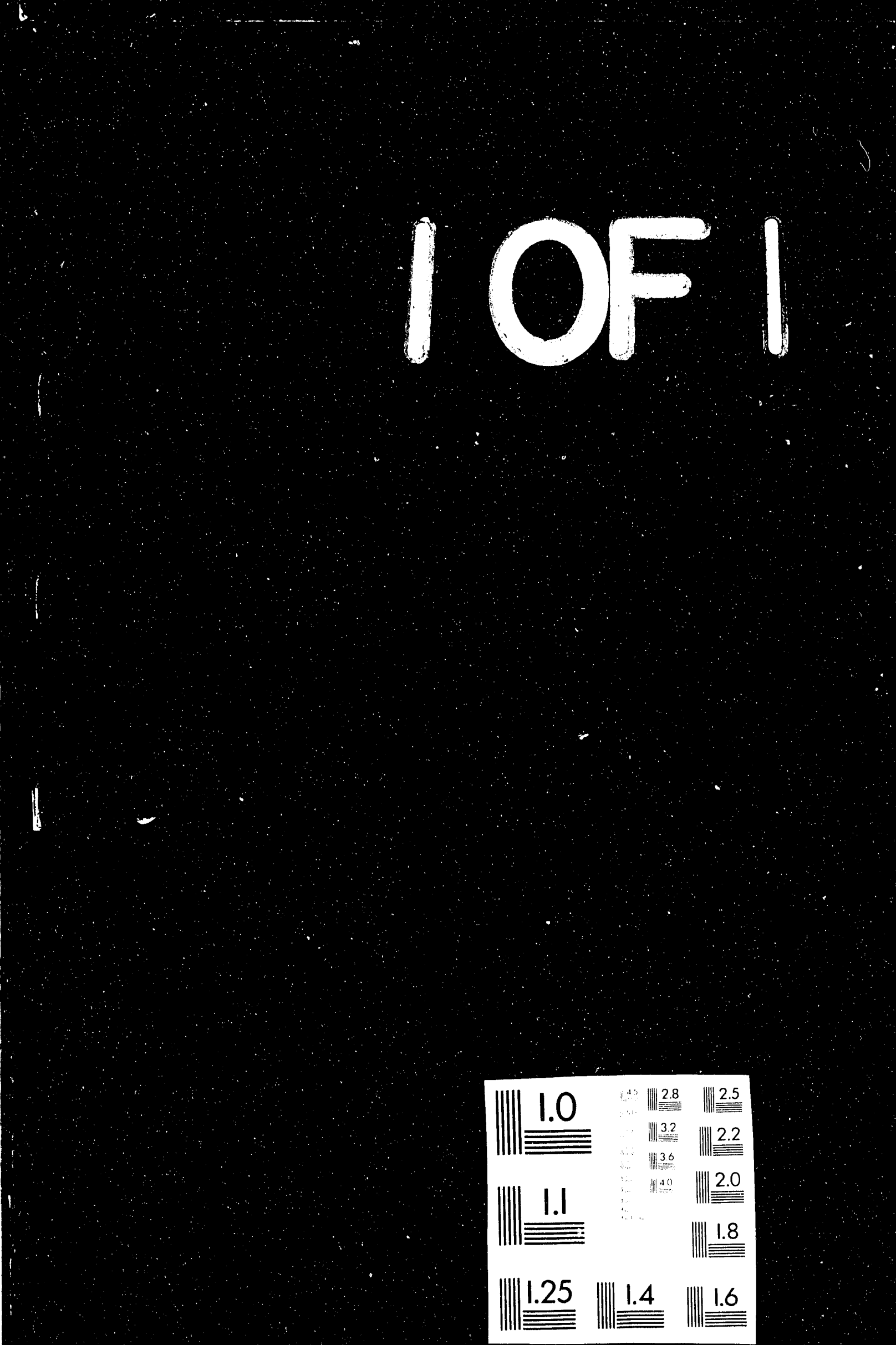

TABLE 1. - Characteristics of the 260-mD fired Berea sandstone sample from routine core analysis and mercury intrusion porosimetry 


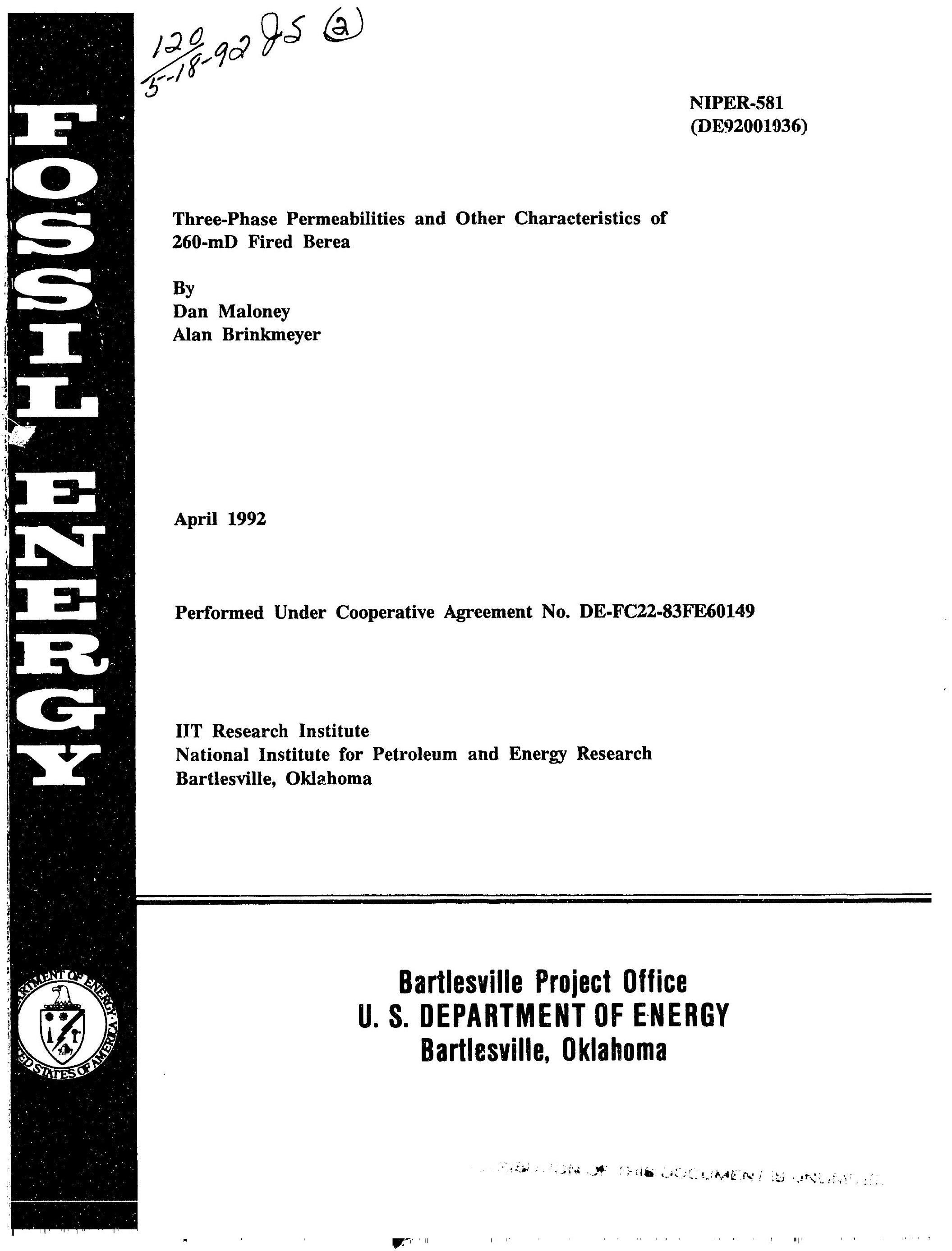




\section{DISCLAIMER}

This report was prepared as an account of work sponsored by an agency of the United States Government. Neither the United States Government nor any agency thereof, nor any of their employees, makes any warranty, express or implied, or assumes any legal liability or responsibility for the accuracy, completeness, or usefulness of any information, apparatus, product, or process disclosed, or represents that its use would not infringe privately owned rights. Reference herein to any specific commercial product. process, or service by trade name, trademark, manufacturer, or otherwise does not necessarily constitute or imply its endorsement, recommendation, or favoring by the United States Government or any agency thereot. The views and opinions of authors expressed herein do not necessarily state or reflect those of the United States Government or any agency thereof.

This report has been reproduced directly from the best available copy.

Available to DOE and DOE contractors from the Office of Scientific and Technical Information, P.O. Box 62, Oak Ridge, TN 37831; prices available from (615)576-8401, FTS 626-8401.

Available to the public from the National Technical Information Service, U.S. Department of Commerce, 5285 Port Royal Rd., Springfield, VA 22161. 
NIPER-581

Distribution Category UC-12.2

Three-Phase Permeabilities and Other Characteristics

NIPER--581

of $260-\mathrm{mD}$ Fired Berea

DE92 001036

\author{
By \\ Dan Maloney \\ Alan Brinkmeyer
}

April 1992

Work Performed Under Cooperative Agreement No. DE-FC22-83FE60149

Prepared for

U.S. Department of Energy

Assistant Secretary for Fossil Energy

\author{
Rhonda L. Patterson, Project Manager \\ Bartlesville Project Office \\ P. O. Box 1398 \\ Bartlesville, OK 74005
}

Prepared by

IIT Research Institute

National Institute for Petroleum and Energy Research

P. O. Box 2128

Bartlesville, OK 74005

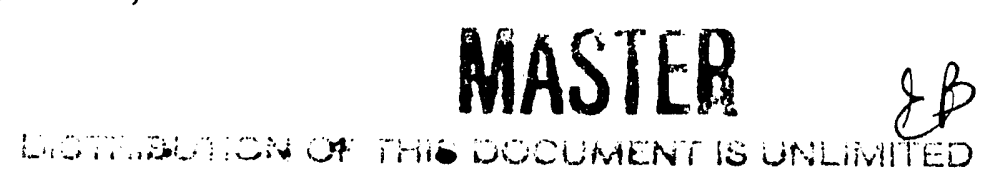




\section{TABLE OF CONTENTS}

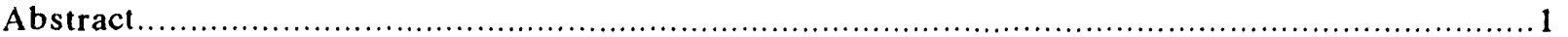

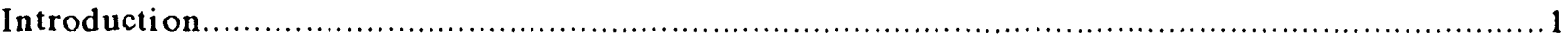

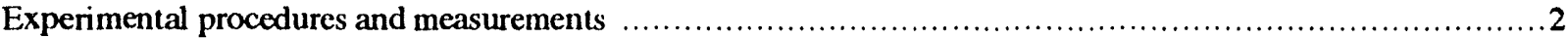

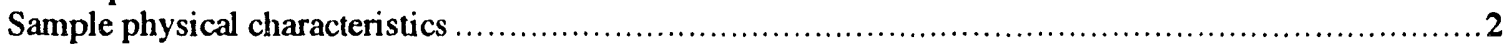

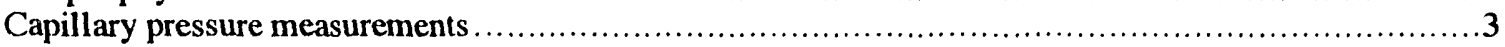

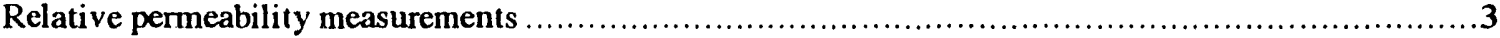

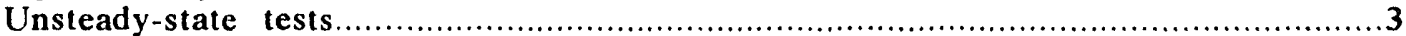

Waterflood test with resistivity and CT saturation measurements .............................

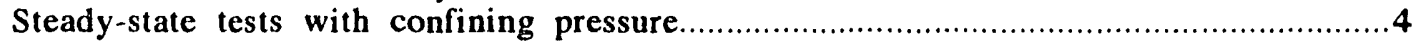

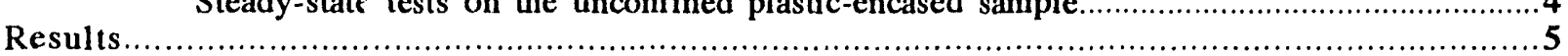

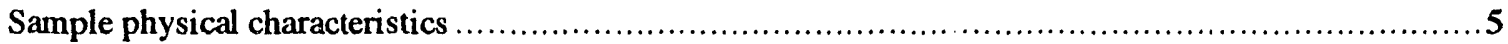

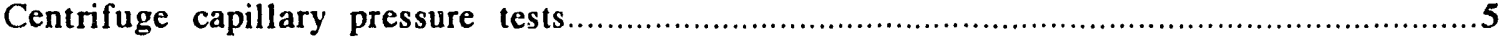

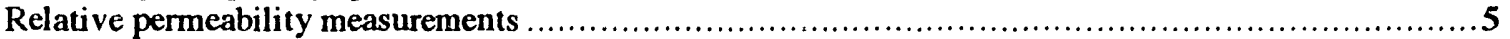

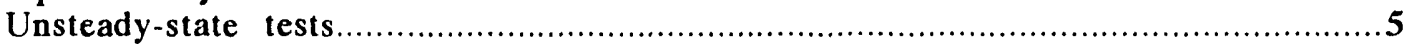

Waterflood test with resistivity and CT saturation measurements ...............................5

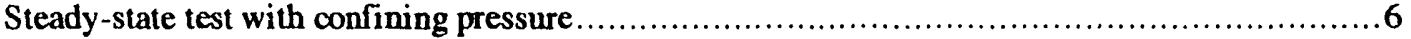

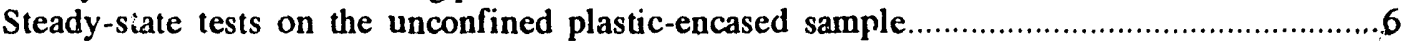

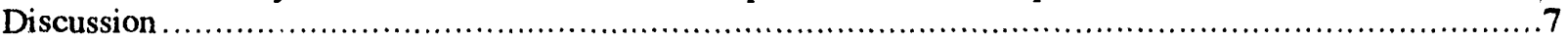

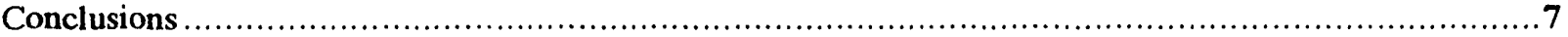

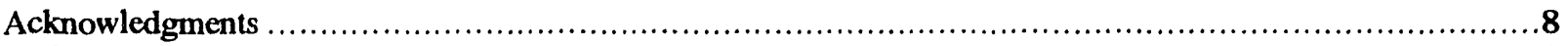

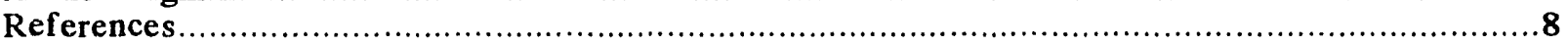

Appendix A - X-ray and microwave attenuation techniques for determining two- and three-phase saturations.... 24

Appendix B - Dual energy X-ray techniques for monitoring three-phase saturations ............................ 26

Appendix C - Using a weight method for fluid production measurements during unsteady-state tests.............. 29

\section{TABLES}

1. Characteristics of the $260-\mathrm{mD}$ fired Berea sandstone sample from routine core analysis and

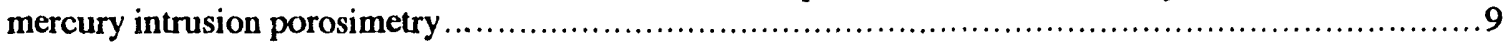

2. Log-normal distribution function characteristics for $260-\mathrm{mD}$ fired Berea sandstone .......................9

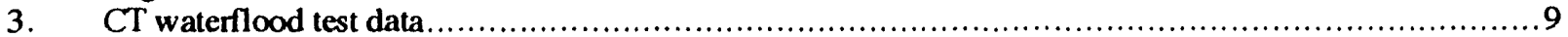

4. $260-\mathrm{mD}$ Berea oil/water steady-state relative permeability results ............................................ 10

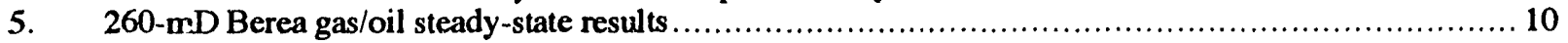

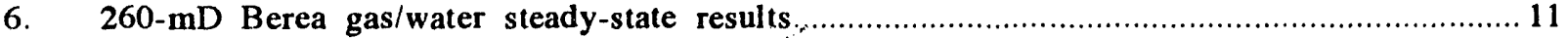

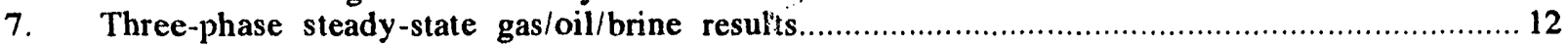

\section{ILLUSTRATIONS}

1. Grain and pore diameter distributions from thin-section analyses, fired $260-\mathrm{mD}$ Berea sandstone ......... 13

2. Mercury intrusion porosimetry results, fired 260-mD Berea sandstone ....................................... 13

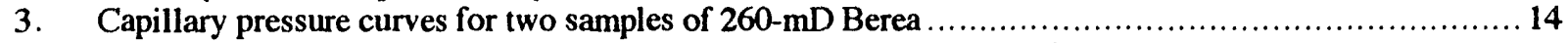

4. Unsteady-state oil/water relative permeability results, fired Berea sandstone with 500 psig

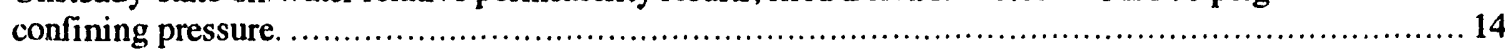

5. Unsteady-state relative permeability results, $260-\mathrm{mD}$ Berea sandstone with injection rates of 400,150

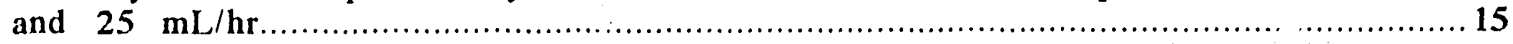

6. Relative permeability ratio versus normalized saturation, $260-\mathrm{mD}$ unsteady-state oil/water relative permeability test results

7. Steady-state oil/water relative permeability results, Berea sandstone with $3,200 \mathrm{psig}$ confining pressure.

Comparison of brine saturations deternined by volumetric and CT techniques during the waterflood

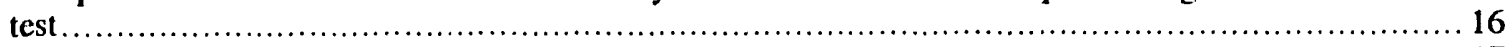

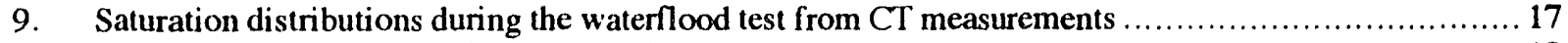

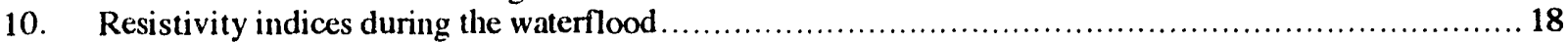




\section{ILLUSTRATIONS - Continued}

Page

11. Unsteady-state oil/water relative permeability results calculated from the $C T /$ waterflood fluid production and pressure drop measurements 19

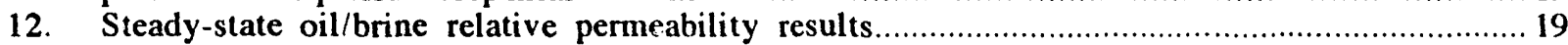

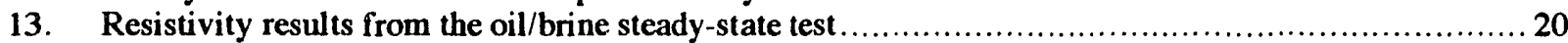

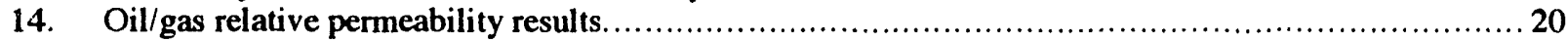

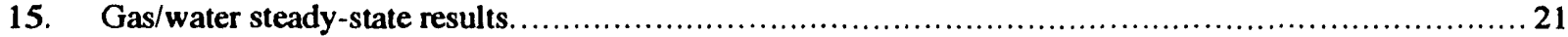

16. DDI saturation trajectories during three-phase relative permeability measurements......................... 21

17. Water relative permeability results from two- and three-phase measurements .......................... 22

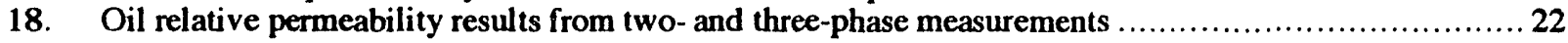

19. Gas relative permeability results from two- and three-phase measurements................................... 23 


\title{
THREE-PHASE RELATIVE PERMEABILITIES AND OTHER CHARACTERISTICS OF 260-mD FIRED BEREA
}

\author{
by Dan Maloney and Alan Brinkmeyer
}

\begin{abstract}
A laboratory investigation was conducted to detcrmine relative permeabilities and other characteristics of a 260 $\mathrm{mD}$ fired Berea sandstone. The mineralogical and physical characteristics of the sample were characterized by XRD tests, thin section analyses, mercury injection tests, and centrifuge capillary pressure and wettability tests. Twophase oil/water relative permeabilities were measured under several stress conditions. Resistivity characteristics of the sample were also evaluated during several of the oil/water tests. Oil/gas and gas/water relative permeabilities were measured during stead'-state tests. Three-phase stcady-state oil/gas/water tests were performed for six DDI saturation trajectories (decreasing brine and oil saturations, increasing gas saturation) in which the sample was not clcancd between saturation trajectories.
\end{abstract}

Oil/water relative permeability results for two different confining-stress conditions were similar. The relative permeability results for unstressed $260-\mathrm{mD}$ Berea samples, however, were different than those of the stressed samples. Applying test results from unconfined core plugs toward studying specific reservoir processes should, therefore, be done with caution. Relative permeability and resistivity results measured during a waterflood test on the $260-\mathrm{mD}$ rock did not agree with measurements from steady-state tests. Water retention at the outlet face of the rock, as shown by $\mathrm{CT}$ scans which were taken during the flood, probably contributed heavily toward the crroneous nature of the unsteady-state relative permeability results. These results show that particular care should be taken when evaluating laboratory resistivity and relative permeability results from tests in which saturation conditions are nonuniform.

Two- and three-phase relative permeabilities for each fluid phase were primarily affected by the saturation of that phase when the wetting phase (brinc) was also present and for conditions of appreciable flow of all of the phases. Water relative permeability versus water saturation results were similar for both two-phase and three-phase flow systems. This result, which indicates that the wetting phase relative permeai:lity is a unique function of the wetting phase saturatio, agrees with the results from other investigations. Within the range of saturation conditions imposed during the laboratory tests, gas relative permeability versus gas saturation results were similar from two-phase gas-brine and threc-phase gas-oil-brinc tests. During these tests, gas relative permeabilities were primarily dependent upon gas saturations. However, lower oil saturations were achicved during threc-phase tests compared to two-phase results. Oil saturations as low as $20 \%$ were achieved with oil flowing in the three-phase system whereas the residual oil saturations during twophase oil/brine tests were approximately $37 \%$. Since mobilization of the oil phase was possible at lower saturations in the three-phase system compared to the twophase system, two-phase oi! relative permeability data were inadequate for describing oil relative permeabilities at oil saturations close to and less than the two-phase residual oil saturation condition. With oil saturations greater than the two-phase residual oil condition, two- and three-phase oil relative permeability results were similar and the threephase oil results tended to fall within the two-phase oil hysteresis envelopes.

\section{INTRODUCTION}

Multiphase flow is a common phenomenon in production from petroleum reservoirs. The initial or primary production from a reservoir may include gas, oil, brinc, or combinations of the three. Later during the productive life of a reservoir, two-phase flow occurs as fluid such as brine is injected into a reservoir to boost production. Finally, if enhanced oil recovery techniques are used to maximize hydrocarbon recovery, multiphase flow processes are virtually guaranteed to occur. With multiphase flow, the fluids compete for the same flow paths through the reservoir rock. The additional resistance to flow is described by normalizing permeabilities for each of the flowing phases at each fluid saturation condition with respect to a base permeability. This measurement and normalization process yields relative permeability data.

The concept of relative permeability for two-phase flow is not new. Work on developing two-phase flow relationships probably began in 1859 , and through the years techniques for using the results have been refined for estimating petroleum reservoir productivity and pcrformance. Efforts to extend the techniques for threephase flow began in 1941, but difficulties limited progress in this area. Three-phase flow experiments for determining relative permeability relationships are very difficul: to perform. Keeping track of fluid saturations in a rock during three-phase steady-state flow experiments was virtually impossible until the recent advent of techniques to monitor in situ fluid saturations directly during flow experiments. Correlations have been developed to predict threc-phase flow effects from two-phase flow measurements, but such correlations are not always correct or accurate. The primary reasons for the limited knowledge 
with respect to three-phase flow systems are the scarcity of accurate three-phase relative permeability laboratory data and laboratory measurement systems.

NIPER has conducted DOE-funded relative permeability research for over 6 years. The objectives of this work have been to improve laboratory measurements of threc-phase relative permeability so that reliable measurements are achieved, and to investigate the influences of rock, fluid, and rock/fluid properties on two- and three-phase rclative permeabilities. This work has yielded improvements in measurement techniques and equipment including the development of an X-ray and microwave scanning instrument for monitoring fluid saturations during relative permeability experiments; the development of a high pressure coreholder that is semitransparent to microwaves; improvement in microwave technology for scanning rocks with thicknesses greater than $2.54 \mathrm{~cm}$, and continual improvements in relative permeability measurement systems and techniques. NIPER's three-phase laboratory investigations have yiclded interesting results. ${ }^{1-8}$ Threephase experiments with Berea sandstone to demonstratc viscous effects on relative permeability ${ }^{3}$ showed that variations in permeabilities as a result of variations in rock characteristics could be seen even for samples cut from the same quarried block of rock; brine relative permeabilitics are a function of the brine saturation; gas relative permeabilities are essentially functions of the gas saturation; oil relative permeabilities werc functions of all three-saturations; and oil and water relative permeabilities were essentially independent of oil viscosity for viscositics in the 1 to $50 \mathrm{cP}$ range. Water relative permeabilities decreased with increasing wetting phase viscosity. Test results were within reasonable repeatability considcring hysteresis effects.

During FY89, NIPER investigated the effects of rock characteristics on relative permeabilities and compared the results of Berea and Bentheimer sandstone samples. ${ }^{4}$ The two sandstones were almost identical except for the greater amount of very small (inicroporosity) and very large (megaporosity) pores for the Berea sandstone compared to the Bentheimer sandstone. Relative permeability results for the two sandstones were noticeably different, and these differences were attributed to the differences in pore size distributions. Comparison of oil-brine flow test results showed that residual oil saturations for the Bentheimer sample were lower than those of the Berca sample; the range of mobile saturations for the Bentheimer sample were broader; and that data from both samples werc subject to hysteresis effects. Under three-phase flow conditions, water relative permeabilities for both samples were influenced by water saturations and not by oil or gas saturations. At equivalent water saturations, the witter relative permeabilities for the Berea were less than those for the Bentheimer sample due to the influence of microporosity. Oil relative permeabilities under threephase flow conditions were affected by all threc-phasc saturations for both samples. However, the Berca oil relative permeabilities were less affected by gas at low gas saturations since the Berea had greatcr megaporosity than the Bentheimer. The Bentheimer results formed a larger three-phase mobile saturation envelope than the Berea results.

Relative permeabilities and other characteristics of a 700 $\mathrm{mD}$ Berea sandstone were measured during FY9(). ${ }^{6}$ Hysteresis was evident in each multiple-cycle centrifuge capillary pressure experiment performed on the $700-\mathrm{mD}$ Berca. The primary effect of the cycle-dependent hysteresis was a reduction in the wetlability index with successive drainage and imbibition cycles. Hysteresis in relative permeability results for the water-wet rock was essentially limited to a shift in nonwetting phase relative permeability versus saturation curves between the first drainage and first imbibition tests in the direction of lower brine saturation for nonwetting phase saturations close to and less than the residual non-wetting phase saturation values. Two-phase measurements did not yield identical results. Mercury intrusion tests demonstrated that the porosimetry tests were uscful for discerning differences in microporosities when characteristics of different samples are compared.

The FY91 research program was designed to build upon the previous results for the project with emphasis on obtaining data which can be used in developing three-phase relative permeability correlations and in describing the relationships among pore and grain size distributions and relative permcabilitics.

\section{EXPERIMENTAL PROCEDURES AND MEASUREMENTS}

\section{Sample Physical Characteristics}

Berea sandstone was selected as the rock material for this investigation. Routine permeability and porosity experiments were conducted with plug samples from scveral blocks of Berea sandstone to find a sample with gas permeability in the 100 to $300 \mathrm{mD}$ range. The $300-\mathrm{mD}$ range was targeted to provide results for comparison with those of the higher-permeability Berea and Bentheimer sandstones previously characterized. ${ }^{4,6}$ A Berea sandstone block with a gas permcability of $270 \mathrm{mD}$ and porosity of $19.6 \%$ was sclected. The brine permeability of the sample was later mcasured as $260-\mathrm{mD}$, so for simplicity, the rock was designated as a $260-\mathrm{mD}$ Berea sandstone. The new sample was selected to be similar to those samples with respect to mincralogy but slightly different with respect to porosity, permeability, and pore and grain shape, size, and number distribution characteristics.

The tests in this investigation were conducted on fired rock samples. Plugs and slabs of the Berea were cut from the block and were fired in an oven at $540^{\circ} \mathrm{C}$ for 24 hours to slabilize clay mincrals. The $540^{\circ} \mathrm{C}$ firing temperature was $460^{\circ}$ lower than the firing temperature that was used for samples tested in FY88, 89, and 90 project years. The lower lïing temperature was selected as a compromise between the need for stabilizing clay minerals while at the same lime preserving other rock properties. Firing at $1,(0)()^{\circ} \mathrm{C}$ often leaves sandstone plugs with a refractory brick-like quality and can shatter some of the sandstone 
grains if the temperature gradient changes abruptly during the heating and cooling processes.

Samples of the fired rock were subjected to routine core analysis, X-ray diffraction (XRD) analysis (bulk and clay minerals), thin section microscopic evaluation, and mercury intrusion porosimetry. Pore and grain size distributions for the fired rock were first characterized by petrographic image analysis (PIA). The PIA system consists of a Dage MTI camcra mounted on a Nikon light microscope. Output from the camera is interfaced with a microcomputer. The microcomputer digitizes the images and performs various petrographic measurements and calculations. Features with dimensions in the sub-micron range were ignored in microscopic grain and pore size number distribution calculations because of microscopic resolution limitations. Five hundred pores and 50() grains were measured by evaluating thin sections with the aid of a petrosgrapic image analysis system. Mercury intrusion porosimetry tests were conducted to further characterize the rock's pore size distribution-particularly in the submicron size range. Volume and pressure measurements from tests in which mercury was forced into the rock pores at pressures from $3.45 \mathrm{kPa}$ to $413 \mathrm{MPa}$ were used to calculate pore diameters and mercury intrusion data.

Plugs of $2.5 \mathrm{~cm}$ diameter and $2.5 \mathrm{~cm}$ length were cut for mercury injection porosimetry tests. Plugs for relative permeability tests with confining pressure were of $3.8 \mathrm{~cm}$ diameter with lengths to $15 \mathrm{~cm}$. A sample with $15.8 \mathrm{~cm}$ length and $1.9 \mathrm{~cm}$ by $5.1 \mathrm{~cm}$ rectangular cross section was prepared for steady-state relative permeability tests. Shallow grooves were cut in the sample along the sample ends and at positions $5 \mathrm{~cm}$ from each end. The grooves were painted with silver conducting paint, then a wrap of copper wire was placed in each groove. The copper wirc was soldered into the groove to provide excellent electrical contact with the sample. The sample was encased in casting plastic (Castolite AP acrylic-polyester resin). Two pressure taps were installed along the top of the sample and were spaced $2.5 \mathrm{~cm}$ from the inlet and outlet rock faces. The pressure drop between the pressure taps and the gage pressure at the upstream pressure tap were measured using Rosemount pressure transmitters. Injection pressures during flow experiments with the plastic-encased sample were kept low - less than 2 atm gauge pressurc - to avoid cracking the plastic and to minimizc gas compressibility effects. A similar sample was prepared for resistivity measurements.

The tests described in this report werc conducted at $25^{\circ}$ C. Nitrogen was used as the gas phase in relative permeability measurements involving gas as onc of the flowing phases. Unless noted otherwise, the test liquids were brine (1\% by weight $\mathrm{NaCl}$ in water) and an isoparaffinic oil (Soltrol 100, a product of Phillips Petroleum Company). The interfacial tension between this brine and oil was 31 to $37 \mathrm{mN} / \mathrm{m}$ at $23^{\circ} \mathrm{C}$. The oil phase was tagged with $10 \%$ by weight iodododecane for steadystate relative permeability tests in which water and oil phases were present. The brine phase was lagged with sodium iodide for gas/water stcady-state tests, so that saturations could be accurately detcrmined by both $X$-ray and microwave attenuation techniques. The terms brine and water are used synonymously within the context of this report.

\section{Capillary Pressure Measurements}

Oil/brine capillary pressure and weltability index characteristics were mcasured for two samples of the 260$\mathrm{mD}$ Berea sandstone. The test fluids were mineral oil and $1 \%$ by weight $\mathrm{NaCl}$ brine. Mcasurements were recorded during drainage and imbibition experiments performed using a Beckman J-6M centrifuge at centrifuge speeds from 200 to 3,800 RPM, corresponding to oil-water capillary pressures from about 0.1 to $17 \mathrm{psi}$. Capillary pressure data were measured during first drainage, first imbibition, and second drainage saturation cycles to provide information on both capillary pressure and wettability charaiteristics. The capillary pressure-saturation relationships were determined using the Rajan ${ }^{9}$ method. Wettability indices were calculated using the USBM technique. ${ }^{10}$

\section{Relative Permeability Measurements}

\section{Unsteady-State Tests}

Several unsteady-state oil/water relative permeability tests were conducted on similar samples of fired Berea. Injection fluids consisted of $1.01 \mathrm{cP}$ brine $(2 \% \mathrm{NaCl}$ by weight in dcionized water) and mineral oil of $23.5 \mathrm{cP}$ viscosity. Tests were conducted with the core plugs subjected to 500 psig confining pressurc. After measuring the brine permeability, each sample was flooded with oil to the residual brine saturation test condition. Unsteady-state measurements were recorded as the test plugs were subsequently nooded with brine (imbibition cycle for a water-wet rock). The JBN 11 method was used to calculate oil and brine permeabilitics. Permabilities were normalized with respect to the permeabilities of the samples to brinc under conditions of complete brine saturation.

A number of additional oil/brinc unsteady-state relative permeability tests were performed on a sample of $260-\mathrm{mD}$ Berea sandstone to evaluate the suitability of a watcrllooding test design criteria that was listed in the literature $(\mathrm{Q} \mu \mathrm{L} \geq 1-5){ }^{12}$ These tests were performed to check whether better agreement could be obtained among unsteady- and steady-state relative permeability measurements when certain experimental criteria were nonored.

\section{Waterflood Test with Resistivity and CT Saturation Measurements}

One waterflood experiment was performed on a sample of the 26()$-\mathrm{mD}$ Berca sandstone in which the electrical propertics and saturation distributions were measured during the test.

The sample was $16 \mathrm{~cm}$ long and had a $2 \mathrm{~cm}$ by $5 \mathrm{~cm}$ rectangular cross-section. The dry rock was outfitted with 
five electrodes which were equally spaced along the length of the sample. The electrodes were attached for measuring the electrical resistances across different segments of the sample. The four-electrode technique (segregation of current and potential electrodes) was used for resistance measurements. The rock was jacketed in an acrylic polyester resin for fluid flow confinement.

The dry, epoxy-jacketed sample was placed in a container which minimized the effects of $X$-ray beam-hardening on the CT scan results. The container was set on an X-ray scanning table and was scanned longitudinally using an 8 $\mathrm{mm}$ wide $\mathrm{X}$-ray beam at a $125 \mathrm{KV}$ power level. The rock was then vacuum saturated with a $7.7 \%$ by weight $\mathrm{KI}$ brine. A scan was taken of the brinc-saturated rock. The iodine component of the brine mixture acted as a tagging agent to increase the $X$-ray attenuation characteristics of the brine phase, thereby allowing better resolution between the brine and oil phases in the rock. The dry CT scans, brincsaturated CT scans, and the CT attenuation numbers for the brine and oil were sufficient for the calibration of the CT for two-phase brine/oil saturation determination as described in a quarterly report for this project. ${ }^{13}$

Electrical resistance was measured across cach combination of the five electrodes at $100 \%$ hrine saturation. The core was then oil-flonded to an irreducible brine saturation condition using a mincral oil of $22 \mathrm{cP}$ viscosity. A $40 \mathrm{~mL} / \mathrm{hr}$ waterflood was conducted on the rock. Resistance measurements and $C T$ scans were recorded with each measurement of the effluent oil and brine volumes.

CT saturations for each rock section were determined by averaging the values of all voxels across the relevant section of the CT scan image. The CT image of the $100 \%$ brine-saturated rock required correction because of excessive attenuation. The longitudinal orientation of the rock within the CT gantry caused grcater X-ray attcnuation than was expected, especially when the rock was saturated with tagged brine. Results for the $100 \%$ brine-saturated rock were therefore calculated from dry scan, porosity, and fluid attenuation measurements. The correction method assumed a uniform porosity for each voxel of the CT image. This assumption of uniform porosity is a limiting factor for CT saturation determination but is not a bad approximation for this homogeneous rock.

\section{Steady-State Tests with Confining Pressure}

A two-phase steady-state oil/water relative permeability test was conducted on a plug of the $260-\mathrm{mD}$ Berea under conditions of 3,200 psig confining pressure. This test was conducted to provide data to compare unconfined sample permeability results with those of a confined sample. The $1.6 \mathrm{cP}$ brine consisted of $6 \% \mathrm{NaCl}$ and $6 \% \mathrm{Nal}$ by wcight in deionized water. The oil was a $1 \mathrm{cP}$ viscosity relined oil (Soltrol 100). The plug was is.itially saturated with brine and was then placed in a corcholder. Changes in pore volume were measured as the confining pressure on the sample was increased to 3,200 psig. Stcady-statc measurements were recorded as brine and oil were simultaneously injected into the rock for two drainage and one imbibition saturation cycles. X-ray absorption techniques were used to monitor Muid saturations within the rock during the test. The $\mathrm{Nal}$ in the brine served as an $X$-ray lag. $X$-ray and microwave altenuation techniques for determining saturations are described in appendix $\mathrm{A}$.

\section{Steady-State Tests on the Unconfined Plastic- Encased Sample}

Two-phase and threc-phase steady-statc oil/water, gas/water, gas/oil, and oil/gas/water relative permeability tests were conducted on the unconfined plastic-encased sample. Between tests, the rock was cleaned with isopropyl alcohol and pentane and dricd with nitrogen gas.

The test fluids used for the two-phase oil/brine test were deionized water containing $1 \%$ by weight $\mathrm{NaCl}$ as the brine phase and Soltrol 100 (an isoparaffinic oil available from Phillips Petroleum Co.) tagged with $10 \%$ by weight iodododecane as the oil phase. A new technique was used to calibratc the X-ray for saturation mcasurements. Scans of the rock when saturated with $1 \% \mathrm{NaCl}$ brine served as the calibration data for the condition of complete brine saturation. Additional scans were taken after the rock was flooded with a tagged brine which had the same X-ray absorption characteristics as the tagged oil. Thus, X-ray calibrations were developed without saturating the rock with oil and without having to interpret fluid saturation distributions within the rock from volumetric measurements. Untagged brine was flooted through the rock to remove all traces of the tagged brine in preparation for the stcady-state relative permeability test. The rock was oil-flooded to residual brine saturation conditions, then two-phase measurements were recorded for an imbibition (i1) and a second drainage (d2) saturation cycle. The microwave scanner was also used to monitor fluid salturations.

After clcaning, the rock was saturated with oil and a stcaldy-state gas/oil test was conducted. Nitrogen gas was used as the gas phase. The rock was cleaned after the gas/oil test. The rock was saturated with brine. Steadystatc gas/brine measurements were recorded for two (rainage saturation cycles and one imbibition cycle.

Threc-phase stcady-statc relative permeability tests were initiated on the sample upon completing the two-phase tcsts. Mcasurements were recorded during six DDI saturation trajectories (decreasing brine and oil saturations, increasing gas saturation). After completing a saturation trajectory, the plug was waterflooded to residual gas and oil saturation conditions. A new saturation trajectory was started by establishing brine and oil flow at a target brine fractional flow ratio before injecting gas into the rock. The target brine fractional flow ratios were selected to provide a spread of three-phase results. Initial oil and brine injection rates were adjusted to yicld a pressure drop across the length of the sample that was equal to approximately hall of the range of the differential pressure transmitter. The first gas rate was adjusted to yicld a pressure drop across the rock sample cqual to approximately $80 \%$ of the differential pressure transmitter range. Permeabilities were calculated from flow rate and pressure drop measurements 
while saturation distributions were calculated from X-ray and microwave scans. Saturation changes along the same saturation trajectory were established by either doubling the gas rate or halving the oil and brine rates, depending upon whether the pressure drop across the plug was closer (o) $50 \%$ or $80 \%$ of full scale. This technique of halving the liquid injection rates or doubling the gas rate was described by Oak et al. ${ }^{18}$ Additional measurements were recorded after doubling the gas rate or halving the oil and brinc rates until either the brine and oil saturations were diminished to residual values or until the oil or brine injection rates were too low for practical measurement. Microwave and X-ray attenuation techniques that were used to determine saturation distributions within the rock during the stcadystate tests are described in appendix A. An alternative method for determining three-phase saturations from $X$-ray results is described in appendix B.

\section{RESULTS}

\section{Sample Physical Characteristics}

Routine core analysis and mercury intrusion porosimetry results are given in Table 1. The permeability and porosity of a plug of the fired rock were 26()$-\mathrm{mD}$ and $19.6 \%$, respectively. XRD results indicate that the rock consists of $92 \%$ quartz, $5 \%$ feldspar (of which half is plagioclase feldspar), $1 \%$ dolomitc, and $2 \%$ illite.

Evaluations of thin sections of the rock showed that the sandstone grain and pore size distributions by number percent for features greater in sizc than $10 \mu \mathrm{m}$ are fairly well represenied with log-normal distribution functions, as shown in Fig. 1. Note that the $y$-axis on the figure is a $\log$ scale while the $x$-axis is a normal probability scalc. Table 2 presents sizes corresponding to 84,50 , and 16 percentile values as well as $\sigma$ results where

$$
\ln \sigma=0.5 \ln \left(\frac{\mathrm{d}_{84}}{\mathrm{~d}_{16}}\right)
$$

Mercury porosimetry results for the sandstone indicate that the median pore diameter by volume is $9.56 \mu \mathrm{m}$. Mercury intrusion results for the sample are shown in Fig. 2 , which is a plot of log specific differential intrusion volume versus pore diameter. Figure 2 indicates that the sample contains a significant volume of pores of size less than 10 microns.

\section{Centrifuge Capillary Pressure Tests}

Figure 3 shows oil/brinc capillary pressure results for two samples of the $260-\mathrm{mD}$ Berea sandstone. The test results were similar for brine saturation fractions to 0.35 and were almost identical for saturation fractions greater than 0.35. USBM wettability indices for the two samples were 1.32 and 1.35 , indicating that the rock is strongly water-wet.

\section{Relative Permeability Measurements}

\author{
Unsteady-State Tests
}

The porosity of the first test plug under ambient pressure conditions was $19.3 \%$ and dropped to $18.3 \%$ as the confining pressure was increased to $500 \mathrm{psig}$. The brine permeability of the plug was $157-\mathrm{mD}$. Relative permeability results for threc imbibition cycles are shown in Fig. 4. The relative permeability versus saturation results for the three imbibition cycles followed the same trends. Hysteresis effects did not appear to be significant in the icst results. Figure 5 shows unstcady-state relative permeabilitics mcasured on a second plug of similar permeability. Injection rates of $25,{ }^{\wedge} 50$, and $400 \mathrm{~mL} / \mathrm{hr}$ yiclded similar oil relative permeability results while the water relative permcability curves shifted in the direction of higher relative permeability with increasing injertion rate. Collcctivcly, though, the unsteady-state results in Figs. 4 and 5 for two different plugs are similar. Figure 6 shows the ratios of water to oil relative permeabilities from the multiple rate test plotted against normalized brine saturations. The trend of the data on Fig. 6 suggests that crrors in residual saturation measurements may liave contributed to the discrepancies among water results from the multiple rate test. Figure 7 shows stcady-state results for a sample confined under a higher stress state. The unstcady-state results from Figs. 4 and 5 are similar to those from the steady-state test on Fig. 7. The steady-state results cover a broader range of water saturations, however.

\section{Waterflood Test with Resistivity and CT Saturation Measurements}

Average saturations from volumetric and CT mcasurements were in suitable agreement considering the resolution of the CT scanner. Figure 8 is a comparison of the volumetric and CT brine saturations during the waterflood test. Table 3 contains pertinent data associated with cach flood profile.

Figurc 9 shows brine saturation profiles as the unsteadystate waterflood progressed. Plot $9 \mathrm{~A}$ shows the saturation profile at the end of the oil flood in which the water saturation was at a residual condition. Flocd profiles $B$ and $\mathrm{C}$ show the brine front moving through the rock. Water breakthrough occurs on profile plot D. Plots $E$ through $H$ show saturation distributions within the center of the sample at several time intervals during the waterflood.

Figure 10 $\log -\log$ plots show changes in resistivity indices with water saturation for regions of the rock between electrodes 1-2, 2-3,3-4, and 4-5. Electrode 1 was at the outlet end of the rock while clectrode 5 was at the inlet end of the sample. The positions of the other clectrodes are shown in Fig. 9 as solid lines. Although the brinc saturation distributions between the resistivity clectrodes in profiles $\mathrm{E}$ through $\mathrm{H}$ in Fig. 9 appear to be uniform and stable, the resistivity indices shown in Fig. 10 continued to vary toward the "straight line" fit between 
the $100 \%$ water and residual water saturation data as the flood progressed. Resistivity index versus saturation trends often appear as straight lines on log-log plots (for examples, check references 14 and 15). Figures 9 and 1() results suggest that the CT scanner did not have the resolution necessary to determine brine saturations to the level that effects the flow of electrical current through the pore spaces, or that saturation data from a vertical planc through the cenıer of the sample were insufficient for characterizing the saturations in the bulk of the sample. This is particularly apparent for the resistivity index between electrodes 4-5 at the inlet end of the rock.

Figure 11 shows unsteady-state oil/water relative permeability results calculated from pressure drop and production measurements recorded during the waterflood test. The data were normalized with respect to the oil permeability of $120-\mathrm{mD}$ at a residual water saturation fraction of 0.274 . The results clcarly appear to be in crror considering the differences among these results and those of Figs. 4, 5, and 7. The water saturation distributions in Fig. 8 show that high water salurations were retained at the outlet face of the rock throughout the flood, indicative of capillary end effects. The actual water saturations at the outlet face from Fig. 9 do not correspond with the water saturations for data sets in Fig. 11, which were calculated by the JBN unsteady-state method. Water retention at the outlet face of the rock probably contributed heavily toward the erroneous nature of thesc unstcady-statc relative permeability results.

This waterflood/CT/resistivity experiment served as a trial test to establish procedures for measuring saturations using the CT scanner during resistivity tests. Perhaps the most interesting finding in this test was the relationship between the resistivity index across adjacent clectrodes and the brine saturation between these clectrodes as the waterflood progressed. Similar trends were shown by Sprunt et al. ${ }^{15}$ A more in-depth look at the relationship between non-uniform saluration distributions and resistivity measurements may be contin ied next year.

\section{Steady-Stare Test with Confining Pressure}

The porosity of the plug was $19.3 \%$ unconfined and dropped to $18.3 \%$ when the confining pressure was increased to $3,200 \mathrm{psig}$. The permeability of the brincsaturated sample was $260-\mathrm{mD}$. Oil and brinc permeabilities were normalized with respect to the permeability of the brine-saturated rock. Stcady-state relative permeability results are shown in Fig. 7. Lillle saturation-history-dependent hysteresis was seen in the data after the first drainage cycle.

\section{Steady-State Tests on the Unconfined Plastic- Encased Sample}

Oil/water relative permeability results for the sample are provided in Table 4 and are shown in Fig. 12. The permeability values were normalized with respect to the brine permeability of the sample when the sample was completely saturated with brine (26()-mD). The brine relative permeability curves followed the same trend for both saluration cycles, whereas lower oil relative permeabilitics resulted at intermediatc salurations during the second drainage cycle. Resistivity measurements were also recorded during the test using the 2-ciectrode method in which the electrodes were centered $5.1 \mathrm{~cm}$ apart along the length of the $15.8-\mathrm{cm}$-long sample. Resistivity index results are shown in Fig. 13. The saturation exponent calculated from the imbibition data was 2.2 compared to the 2.4 result from the drainage data. Vicwed collectively, the imbibition and drainage resistivity data follow the same trend. This is consistent with the brine relative permeability results. The saturation exponent for the combincd imbibition and drainage data is 2.2. Note that the resistivity trends in Fig. 10 for conditions of residual water and complete water saturations (first twe points on cach graph) are similar to those of Fig. 13.

The limited results from the gas/oil steady-state test are given in Table 5 and are shown in Fig. 14. The results are for conditions in which no residual water saturation was present. The quality of the gas/oil data is suspect. Gas/water two-phase results are listed in Table 6 and are presented in Fig. 15. The gas relative permeability curves were similar for the two drainage cycles, while the imbibition results were significantly different. Toward the end of the imbibition cycle as the brine permeability at residual gas saturation conditions was measured, the brine permeability dropped, suggesting fines migration. The flow direction was reversed, restoring the permeability. The forward flow direction was resumed for the second drainage cycle. The gas relative perneability curves for the two drainage cycles are similar, as are the brine relative permeabilitics on the first drainage and imbibition curves. Other discrepancies in the data may be related to eycle dependent hysteresis, sample plugging, or the temporary change in llow directions. Further tests to examine the causes of the discrepancies were not possible because of time limitations.

The saturation trajectories that were achieved during the threc-phase steady-statc test are shown in Fig. 16. Threephase water relative permeability results are provided in Table 7. Two- and three-phase water relative permeabilitics are shown in Fig. 17. The two-phase and threc-phase water relative permeabilitics follow the same trend, indicating that the water relative permcabilities for the sample under both two- and three-phase flow conditions are primarily influenced by the water saturation conditions of the sample. Two- and threc-phase oil results are plotted in Fig. 18. The two- and threc-phase oil relative permeabilitics also followed similar trends, indicating that for this rock, the oil relative permeabilities in multiphase systems were primarily affected by oil saturations. Twoand threc-phase gas relative permeabilitics are plotted in Fig. 19. The two-phase gas results in Fig. 19 are for the first imbibition and second drainage tests in which the greatest differences in gas results occurred. The three-phase gals results fell within an envelope defined by these twophase results. 


\section{DISCUSSION}

Most of the relative permeability results in this report were normalized with respect to the water permeability under conditions of complete water saturation. Previous results from this project were normalizec with respect to the oil permeability from two-phase oil/water tests at residual water saturation conditions. The change in normalization procedures was made to provide consistency with the methods of other investigators.

The relative permeability curves for confined and unconfined samples of the same rock were not identical. Results for samples confined at 50) psig and 3,200 psig were similar, suggesting that the application of soinc confining pressure is better than testing unconfined samples when test results must be related to reservoir processes in which high net confining pressures arc present. Changes in pore dimensions and closure of microfractures with stress as demonstrated by the characteristic decrease in pore volume with stress that most rocks exhibit are probably responsible for much of the differences in unconfined and confined test results. However, the comparisons of two- and three-phase relative permeabilities in this report for unconfined samples are still considered valid as both types of tests were conducted under the same net confining stress conditions. Since thin sections are cut from unconfined rock samples, comparisons of pore size distributions from thin sections with permeability results are most applicablc for rock samples $t$ ' at are tested in the unconfined statc.

The rock was not cleaned after each DDI saturation cycle during the threc-phase tests. Instcad, the rock was flooded with brine to drive the oil and gas saturations to residual conditions before starting a ncw saturation trajectory. Two- and three-phase relative permeabilities for a fluici phase were primarily affected by the saturation of that phase for tests in which the welting phase (water) was also present. Two- and threc-phase results for a particular phase with respect to the saturation of that phase were similar when the wetting phase was one of the phases present in the rock, considering hysteresis. This result is in agreement with those of Leverett and Lewis ${ }^{20}$ for conditions of appreciable flow of all threc-phases. Threcphase results for cach phase tended to fall within the twophase hysteresis envelope. However, lower oil saturations were achicved during three-phase tests compared to twophase results. Oil saturations as low as $20 \%$ were achieved with oil flowing in the threc-phase system whereas the residual oil saturations during two-phase oil/brine tests were approximately $37 \%$. Since mobilization of the oil phase was possible at lower saturations in the three-phase system compared to the two-phase system, two-phase oil relative permeability data were inadcquate for describing oil relative permeabilitics at oil saturations close to and less than the two-phase residual oil salturation condition. With oil saturations greater than the two-phase residual oil condition, two- and threc-phase oil relative permeability results were similar and the three-phase oil results tended to fall within the two-phase oil hysteresis cnvelope.
Relierences 16 ihrough 20 provide threc-phase results from some other investigations for comparison.

The results from the $\mathrm{CT} / \mathrm{resistivity/waterflood} \mathrm{test}$ suggest that particular care should be laker when evaluating resistivity or relative permcability duta for rocks containing non-uniform saturation distributions.

\section{CONCLUSIONS}

Some conclusions from this work are as follows:

1. This $260-\mathrm{mD}$ fired Berea sandstone was strongly walcr-wct. USBM wctlability indices from oil/water centrifuge test measurements were close to 1 .

2. Unstcady-state and steady-state oil,'water relative permeability results for the rock were similar when the rock was tcstcd with confining pressure for confining pressures in the 500 to 3,200 psig range. The relative permeability curves for confined and unconfined samples of the same rock were not identical, suggesting that care should be taken when applying test results from unconlined core plugs toward studying reservoir processes. However, the comparisons of two- and three-phase relative permcabilitics in this report for unconfined samples are still considered valid as both types of tests were conducted under the same net confining stress conditions.

3. Particular care should be taken when evaluating resistivity and relative permeability results from tests in which saluration conditions are non-uniform. The relative permcability and resistivity results measured during a waterflood test on the $260-\mathrm{mD}$ rock did not agree with measurements from stcady-statc issts. Water retention at the outlet face of the rock, as shown by CT scans which were taken during the flood, probably centributed heavily toward the crroneous nature of the unsteady-state relative permcability results. Further investigation into relationships between resistivities and non-uniform saturation distributions is required.

4. Water relative permeability versus water saturation results were similar for both two-phase and three-phase flow systems. This result, which indicates that the welling phase relative permeability is a urique function of the welling phase saturation agrees with the results from other investigations.

5. Within the range of saturation conditions imposed during the laboratory tests and when the wetting phase (water) was also present in the system, two- and threephase oil relative permeabilitics were primarily dependent upon oil saturations while gas results were primarily dependent upon gas salurations. Threc-phase results for cach phase tended to fall within the hysteresis envelope from two-phase results.

6. Lower residual saturation conditions than those achicved at the end of two-phase processes resulted during the threc-phase tests. Oil saturations as low as 20\% were achicved with oil flowing in the threc-phase system whereas the residual oil saturations during two-phase tests were approximatcly $37 \%$. 
7. The three-phase saturation envelope or range in saturations with three flowing phases for the $260-\mathrm{mD}$ Berea sample was relatively small.

\section{ACKNOWLEDGMENTS}

This work was performed for the U. S. Department of Energy (DOE) under Cooperative Agreement DE-FC2283F'60149. The authors thank Willis Waldorf, Ron Masias, Mike Crocker, and Liviu Tomutsa, ail of NIPER, for their assistance in the laboratory with steady-state relative permeability, centrifuge capillary pressure, and CT scan measurements. Appreciation is also extended to Eddie Lou, who worked on the project during the summer under an AWU Scholarship, for conducting unsteady-state relative permeability tests and to Jesus Betancourt of INTEVEP for his valuable contributions in the development of unsteady-state relative permeability and centrifuge capillary pressure computer programs to facilitate data analysis. Finally, we thank the NIPER management and personnel who reviewed this manuscript, and Rhonda Patterson, the DOE Project Manager, for her support.

\section{REFERENCES}

1. Parmeswar, K., and N. Maerefat. A Comparison of Methods for the Presentation of Three-Phase Relative Permeability Data. Proc. of the Soc. Pet. Eng. 56th Califomia Regional Meeting, Oakland, (April 2-4, 1986), pp. 151-157.

2. Parmeswar, R., N. Maerefat, and A. Brinkmeyer. Preliminary Results on the Effect of Fluid Viscosity on ThreePhase Relative Permeability. DOE Report NIPER-296, 1987.

3. Maloney, D., S. Mahmood, and M. Honarpour. The Effects of Viscous Forces on Three-Phase Relative Permeability. DOE Report NIPER-392, 1989.

4. Maloney, D., M. Honarpour, and A. Brinkmeyer. The Effects of Rock Characteristics on Relative Permeability. DOE Report NIPER-441, 1990 (NTIS Order NO. DE9000212).

5. Honarpour, M. and S. Mahmood. Relative Permeability Measurements: An Overview. SPE Tech. Today Series, J. Pet. Tech., August, 1988.

6. Maloney, D., A. Brinkmeyer, and M. Honarpour. Rulative Permeabilities and Other Characteristics of 700 Millidarcy, Fired Berea Sandstone. DOE Report NIPER-496, October, 1990.

7. Honarpour, M., D. Maloney, S. Suzuki, and L. Tomutsa. Investigation of Cycle Dependent Centrifuge Capillary Pressure and Wettability Index Behavior for Water-wet High Permeability Sandstones. Paper SCA 9006 Pres. at the Fourth Annual SCA Technical Conference, Dallas, TX. August 15-16, 1990.
8. Honarpour, M. and D. Maloney. Relative Permeability Technology and Applications. Paper SCA 9008 Pres. at the 4th Annual SCA Tech. Conf., Dallas, TX, Aug. 15-16, 1990.

9. Rajan, R. Theoretically Correct Analytical Solution for Calculating Capillary Pressure-Saturation From Centrifuge Experiments. Paper J. Pres. at the SPWLA 27th Annual Logging Symposium, June, 1986.

10. Donaldson, E. and P. Lorenz. Wettability Determination and Its Effec: on Recovery Efficiency. SPEJ, March, 1969, pp. 13-20.

11. Johnson, E., D. Bossler, and V. Naumann. Calculation of Relative Permeability from Displacement Experiments. Trans. AIME, December, 1958.

12. Batycky, J., F. McCaffery, P. Hodgins, and D. Fisher. Interpreting Relative Permeability and Wettability From Unsteady-State Displacement Measurements. SPEJ, June, 1981, pp. 296-308.

i?. Maloney, D. Quarterly Technical Report for April I June 30, 1991. Volume II. Energy Production Research. DOE Report NIPER-545,

14. Lyle, W. and W. Mills. Effect of Nonuniform Core Saturation on Laboratory Determination of the Archie Saturation Exponent, SPEFE, March 1989.

15. Sprunt, E., K. Desal, M. Coles, R. Davis, E. Muegge. "CT-scan-Monitored Electrical Resistivity Measurements Show Probiems Achieving Homogeneous Saturation", SPE Formation Evaluation, June 1991, p. 134-140

16. Oak, M., L. Baker, and D. Thomas. Three-Phase Relative Permeability of Berea Sandstone. Paper SPE/DOE 17370 Pres. at the SPE/DOE Enhanced Oil Recovery Symposium, Tulsa, OK, April 17-20, 1988.

17. Oak, M., and R. Ehrlich. A New X-ray Absorption Method for Measurement of Three-Phase Relative Permeability. SPE Reservoir Engineering, February, 1988, pp. 199-206.

18. Oak, M. Three-Phase Relative Permeability of Berea Sandstone. Paper SPE/DOE 20183 Pres. at the SPE/DOE 7th Symposium on Enhanced Oil Recovery. Tulsa, OK April 2225, 1990.

19. Dria, D., G. Pope and K. Sepehrnoori. Three-Phase Gas/Oil/Brine Relative Permeabilities Measured Under Carbon Dioxide Flooding Conditions. Paper SPE/DOE 20184 Pres. at the DOE/SPE 7th Symposium on Enhanced Oil Recovery, Tulsa, OK, April 22-25, 1990.

20. Leverett, M. and W. Lewis. Steady Flow of Gas-OilWater Mixtures Through Unconsolidated Sands. Trans. AIME, 1941, pp. $107-116$. 
TABLE 1. - Characteristics of the 260)-mD fired Berea sandstone sample from routine core analysis and mercury intrusion porosimetry

$\begin{array}{lc}\text { Air permeability, } \mathrm{mD} & 260.0 \\ \text { Porosity, } \% & 19.6 \\ \text { Total porc surface arca, } \mathrm{m} 2 / \mathrm{g} & 4.41 \\ \text { Median pore diameter (by volume), } \mu \mathrm{m} & 9.56\end{array}$

TABLE 2. - Log-normal distribution function characteristics for 260-mD fired Berea sandstone

\begin{tabular}{|c|c|c|c|c|}
\hline Feature & $\mathrm{d} 84^{1}, \mu \mathrm{m}$ & d 50, $\mu \mathrm{m}$ & $d_{16}, \mu m$ & $\sigma^{2}$ \\
\hline Grains & 205 & 139 & 93 & 1.485 \\
\hline Pores & 143 & 84 & 51 & 1.674 \\
\hline
\end{tabular}

1. $84 \%$ of the grains (by number) are smaller than the $\mathrm{d} 84$.

2. $\ln \sigma=0.5 \ln \left(\mathrm{d}_{84} / \mathrm{d}_{16}\right)$.

TABLE 3. - Injection and saturation data recorded during an unsteady-state waterflood test using $260 \mathrm{mD}$ Berea sandstone

\begin{tabular}{|c|c|c|c|c|c|c|c|}
\hline $\begin{array}{l}\text { Data } \\
\text { Set }\end{array}$ & $\begin{array}{c}\text { PV } \\
\text { Injected }\end{array}$ & $\begin{array}{c}S_{w} \\
V_{0 l}\end{array}$ & $\begin{array}{l}S_{W} \\
C T\end{array}$ & $\begin{array}{c}S_{W}-C T \\
\text { Electrode } 1-2\end{array}$ & $\begin{array}{c}S_{W}-C T \\
\text { Electrode } \quad 2-3\end{array}$ & $\begin{array}{c}\mathrm{S}_{\mathrm{w}}-\mathrm{CT} \\
\text { Electrode } 3-4\end{array}$ & $\begin{array}{c}\mathrm{S}_{\mathrm{w}}-\mathrm{CT} \\
\text { Electrode } \\
4-5\end{array}$ \\
\hline A & 0.00 & 0.274 & 0.286 & 0.331 & 0.267 & 0.249 & 0.232 \\
\hline B & 0.24 & 0.332 & 0.329 & 0.330 & 0.269 & 0.247 & 0.442 \\
\hline $\bar{C}$ & 0.38 & 0.446 & 0.452 & 0.312 & 0.396 & 0.505 & 0.540 \\
\hline D & 0.55 & 0.595 & 0.594 & 0.594 & 0.575 & 0.585 & 0.618 \\
\hline$E$ & 0.60 & 0.604 & 0.607 & 0.612 & 0.585 & 0.599 & 0.629 \\
\hline$F$ & 0.77 & 0.616 & 0.625 & 0.644 & 0.601 & 0.609 & 0.643 \\
\hline$G$ & 1.10 & 0.619 & 0.617 & 0.637 & 0.596 & 0.602 & 0.632 \\
\hline $\mathrm{H}$ & 2.80 & 0.622 & 0.620 & 0.639 & 0.598 & 0.604 & 0.634 \\
\hline
\end{tabular}


TABLE 4. - 260-mD Berea oil/water steady-state relative permeability results normalized with respect to $k_{w}=260 \mathrm{mD}$ at $S_{w}=1.0$

\begin{tabular}{|c|c|c|c|c|c|c|}
\hline $\mathbf{k}_{\mathbf{w}}, \mathbf{m D}$ & $\mathrm{k}_{\mathrm{o}}, \mathrm{mD}$ & $\mathbf{k}_{\mathbf{r w}}$ & $k_{r o}$ & $\mathbf{R}_{\mathbf{t}} / \mathbf{R}_{\mathbf{0}}$ & $\mathbf{S}_{\mathbf{w}}$ & \\
\hline 275.66 & 0.00 & $1.052 E+00$ & $0.000 \mathrm{E}+00$ & 1.00 & 1.000 & i1* \\
\hline 0.00 & 181.00 & $0.000 \mathrm{E}+00$ & $6.962 \mathrm{E}-01$ & 9.22 & 0.339 & \\
\hline 2.38 & 107.90 & $9.154 \mathrm{E}-03$ & $4.150 \mathrm{E}-01$ & 6.60 & 0.459 & \\
\hline 3.75 & 65.70 & $1.442 \mathrm{E}-02$ & $2.527 \mathrm{E}-01$ & 5.00 & 0.475 & \\
\hline 5.28 & 43.60 & $2.031 \mathrm{E}-02$ & $1.677 \mathrm{E}-01$ & 4.20 & 0.534 & \\
\hline 7.98 & 6.25 & $3.069 \mathrm{E}-02$ & $2.404 \mathrm{E}-02$ & 3.11 & 0.570 & \\
\hline 9.91 & 1.30 & $3.812 \mathrm{E}-02$ & $5.000 \mathrm{E}-03$ & 2.59 & 0.568 & \\
\hline 10.20 & 0.00 & $3.923 \mathrm{E}-02$ & $0.000 \mathrm{E}+00$ & 2.76 & 0.629 & \\
\hline 9.95 & 0.25 & $3.827 \mathrm{E}-02$ & $9.615 \mathrm{E}-04$ & 2.56 & 0.637 & $\mathbb{D}$ \\
\hline 9.76 & 1.29 & $3.754 \mathrm{E}-02$ & $4.962 \mathrm{E}-03$ & 2.65 & 0.620 & \\
\hline 8.37 & 6.13 & $3.219 \mathrm{E}-02$ & $2.358 \mathrm{E}-(02$ & 3.01 & 0.617 & \\
\hline 6.19 & 16.40 & $2.381 \mathrm{E}-02$ & $6.308 \mathrm{E}-02$ & 3.51 & 0.561 & \\
\hline 3.50 & 34.60 & $1.346 \mathrm{E}-02$ & $1.331 \mathrm{E}-01$ & 4.43 & 0.519 & \\
\hline 3.10 & 54.90 & $1.192 \mathrm{E}-02$ & $2.112 \mathrm{E}-01$ & 5.04 & 0.480 & \\
\hline 2.30 & 69.20 & $8.846 \mathrm{E}-03$ & $2.662 \mathrm{E}-01$ & 5.57 & 0.458 & \\
\hline 0.00 & 128.60 & $0.000 \mathrm{E}+00$ & $4.946 \mathrm{E}-01$ & 7.78 & 0.407 & \\
\hline
\end{tabular}

*Saturation cycle, $\mathrm{i}=$ imbibition, $\mathrm{d}=$ drainage

Resistivity results: $\quad \mathrm{i} 1, \mathrm{R}_{\mathrm{V}} \mathrm{R}_{\mathrm{O}}=0.99\left(\mathrm{~S}_{\mathrm{W}}-2.15\right) ; \mathrm{R}=0.97$

d2, $R_{V} / R_{0}=0.88\left(S_{W}-2.20\right) ; R=0.99$

TABLE 5. - 260-mD Berea gas/oil steady-state results normalized with respect to $k_{W}=260 \mathrm{mD}$ at $S_{w}=1.0$

\begin{tabular}{|c|c|c|c|c|c|}
\hline $\mathrm{k}_{\mathbf{g}, \mathrm{mD}}$ & $k_{\mathbf{0}}, \quad \mathbf{m D}$ & $\mathrm{krg}_{\mathrm{rg}}$ & kro & $S_{0}$ & $s_{g}$ \\
\hline 234.0 & 0.0 & $8.999 \mathrm{E}-(01$ & $0.000 \mathrm{E}+00$ & 0.000 & 1.000 \\
\hline 0.0 & 183.4 & $0.00(0 \mathrm{E}+(0)$ & $7.054 \mathrm{E}-(01$ & 1.000 & 0.000 \\
\hline 136.0 & 0.0 & $5.231 \mathrm{E}-(01$ & $0.000 \mathrm{E}+00$ & 0.409 & 0.591 \\
\hline 37.9 & 38.8 & $1.458 \mathrm{E}-01$ & $1.492 \mathrm{E}-01$ & 0.528 & 0.472 \\
\hline 19.9 & 45.1 & $7.654 \mathrm{E}-02$ & $1.735 \mathrm{E}-01$ & 0.618 & 0.382 \\
\hline 8.2 & 77.2 & $3.154 \mathrm{E}-(02$ & $2.969 \mathrm{E}-01$ & 0.841 & 0.159 \\
\hline 2.3 & 106.1 & $8.846 \mathrm{E}-03$ & $4.081 \mathrm{E}-01$ & 0.929 & 0.071 \\
\hline 0.184 & 192.5 & $7.077 \mathrm{E}-(04$ & $7.404 \mathrm{E}-01$ & 0.997 & 0.003 \\
\hline 0.0 & 225.7 & $0.000 \mathrm{E}+00$ & 8.681.E-01 & 0.998 & 0.002 \\
\hline
\end{tabular}


TABLE 6. - 260-mD Berea gas/water steady-state results normalized with respect to $k_{w}=260 \cdot \mathrm{mD}$ at $S_{w}=1.0$

\begin{tabular}{cccccc}
\hline $\mathbf{k}_{\mathbf{w}}, \mathbf{m D}$ & $\mathbf{k} \mathbf{g}, \mathbf{m D}$ & $\mathbf{k}_{\mathbf{r w}}$ & $\mathbf{k} \mathbf{r g}$ & $\mathbf{S}_{\mathbf{w}}$ & \\
& & & & & \\
\hline 0 & 260 & $0.000 \mathrm{E}+00$ & $1.000 \mathrm{E}+00$ & 0.000 & $\mathrm{~d} \mathbf{1}^{*}$ \\
260 & 0 & $1.000 \mathrm{E}+00$ & $0.000 \mathrm{E}+00$ & 1.000 & \\
114.3 & 4 & $4.396 \mathrm{E}-01$ & $1.538 \mathrm{E}-02$ & 0.942 & \\
80 & 21.6 & $3.077 \mathrm{E}-01$ & $8.308 \mathrm{E}-02$ & 0.890 & \\
34.5 & 58.7 & $1.327 \mathrm{E}-01$ & $2.258 \mathrm{E}-01$ & 0.764 & \\
22.77 & 77.4 & $8.758 \mathrm{E}-02$ & $2.977 \mathrm{E}-01$ & 0.709 & \\
12.1 & 90.3 & $4.654 \mathrm{E}-02$ & $3.473 \mathrm{E}-01$ & 0.642 & \\
2.27 & 134.9 & $8.731 \mathrm{E}-03$ & $5.188 \mathrm{E}-01$ & 0.547 & \\
0 & 174.8 & $0.000 \mathrm{E}+00$ & $6.723 \mathrm{E}-01$ & 0.439 & \\
2.5 & 138.9 & $9.615 \mathrm{E}-03$ & $5.342 \mathrm{E}-01$ & 0.517 & $\mathrm{i} 1$ \\
3.6 & 97.8 & $1.385 \mathrm{E}-02$ & $3.762 \mathrm{E}-01$ & 0.556 & \\
9.2 & 58.6 & $3.538 \mathrm{E}-02$ & $2.254 \mathrm{E}-01$ & 0.593 & \\
14.2 & 42.9 & $5.462 \mathrm{E}-02$ & $1.650 \mathrm{E}-01$ & 0.635 & \\
16.8 & 26.4 & $6.462 \mathrm{E}-02$ & $1.015 \mathrm{E}-01$ & 0.671 & \\
21.97 & 5.45 & $8.450 \mathrm{E}-02$ & $2.096 \mathrm{E}-02$ & 0.725 & \\
33.5 & 0.785 & $1.288 \mathrm{E}-01$ & $3.019 \mathrm{E}-03$ & 0.775 & \\
66.5 & 0.0 & $2.558 \mathrm{E}-(01$ & $0.000 \mathrm{E}+00$ & 0.867 & \\
57.1 & 2.64 & $2.196 \mathrm{E}-01$ & $1.015 \mathrm{E}-02$ & 0.896 & $\mathrm{~d}$ \\
22.5 & 35.8 & $8.654 \mathrm{E}-02$ & $1.377 \mathrm{E}-01$ & 0.766 & \\
9.0 & 61.8 & $3.462 \mathrm{E}-02$ & $2.377 \mathrm{E}-01$ & 0.698 & \\
2.0 & 108.3 & $7.692 \mathrm{E}-03$ & $4.165 \mathrm{E}-01$ & 0.612 & \\
0.0 & 151.3 & $0.000 \mathrm{E}+00$ & $5.819 \mathrm{E}-01$ & 0.538 & \\
& & & & & \\
\hline
\end{tabular}

*Saturation cycle, $i$ = imbibition, $d=$ drainage. 
TABLE 7. - Three-phase steady-state gas/oil/brine results normalized with respect to $k_{w}=260-\mathrm{mD}$ when $S_{w}=1.0$

\begin{tabular}{|c|c|c|c|c|c|c|c|c|c|}
\hline $\begin{array}{l}\mathbf{k g} \\
\mathbf{m D}\end{array}$ & $\begin{array}{l}k_{w} \\
m \mathbf{D}\end{array}$ & $k_{0}$ & $k_{r g}$ & $k_{r w}$ & kro & $\mathbf{s}_{\mathrm{g}}$ & $S_{w}$ & $S_{0}$ & \\
\hline 0.05 & 7.2 & 0.375 & $1.923 \mathrm{E}-04$ & $2.769 \mathrm{E}-02$ & $1.442 \mathrm{E}-03$ & 0.090 & 0.608 & 0.302 & $\mathrm{T1}^{*}$ \\
\hline 0.288 & 6.66 & 0.211 & $1.108 \mathrm{E}-03$ & $2.562 \mathrm{E}-02$ & $8.115 E-04$ & 0.119 & 0.600 & 0.281 & \\
\hline 0.53 & 5.4 & 0.22 & $2.038 \mathrm{E}-03$ & $2.077 \mathrm{E}-(02$ & $8.462 \mathrm{E}-04$ & 0.107 & 0.613 & 0.280 & \\
\hline 1.39 & 4.6 & 0.07 & $5.346 \mathrm{E}-03$ & $1.769 \mathrm{E}-02$ & $2.692 \mathrm{E}-04$ & 0.163 & 0.592 & 0.245 & \\
\hline 1.54 & 4.6 & 0.092 & $5.923 \mathrm{E}-03$ & $1.769 \mathrm{E}-02$ & $3.538 \mathrm{E}-04$ & 0.194 & 0.590 & 0.216 & \\
\hline 2.177 & 3.72 & 0.087 & $8.373 \mathrm{E}-03$ & $1.431 \mathrm{E}-02$ & $3.346 \mathrm{E}-04$ & 0.223 & 0.571 & 0.206 & \\
\hline 8.62 & 3.09 & 0.052 & $3.315 \mathrm{E}-02$ & $1.188 \mathrm{E}-02$ & $2.000 \mathrm{E}-04$ & 0.271 & 0.521 & 0.208 & \\
\hline 0.726 & 3.22 & 1.24 & $2.792 \mathrm{E}-03$ & $1.238 \mathrm{E}-02$ & $4.769 \mathrm{E}-03$ & 0.117 & 0.526 & 0.357 & $\mathrm{~T} 2$ \\
\hline 1.28 & 2.19 & 0.71 & $4.923 \mathrm{E}-03$ & $8.423 E-03$ & $2.731 E-03$ & 0.186 & 0.492 & 0.322 & \\
\hline 2.48 & 2.28 & 0.71 & $9.538 \mathrm{E}-03$ & $8.769 \mathrm{E}-03$ & $2.731 \mathrm{E}-03$ & 0.200 & 0.483 & 0.317 & \\
\hline 4.56 & 1.55 & 0.33 & $1.754 \mathrm{E}-02$ & $5.962 \mathrm{E}-03$ & $1.269 \mathrm{E}-03$ & 0.220 & 0.458 & 0.321 & \\
\hline 8.95 & 1.51 & 0.32 & $3.442 \mathrm{E}-02$ & $5.808 \mathrm{E}-03$ & $1.231 \mathrm{E}-03$ & 0.221 & 0.463 & 0.317 & \\
\hline 19.2 & 0.63 & 0.3195 & $7.385 \mathrm{E}-02$ & $2.404 \mathrm{E}-03$ & $1.229 \mathrm{E}-03$ & 0.280 & 0.425 & 0.294 & \\
\hline 0.16 & 0.98 & 3.39 & $6.154 \mathrm{E}-04$ & $3.758 \mathrm{E}-03$ & $1.304 \mathrm{E}-02$ & 0.147 & 0.493 & 0.360 & T3 \\
\hline 0.47 & 0.72 & 1.71 & $1.808 \mathrm{E}-03$ & $2.769 \mathrm{E}-03$ & $6.577 \mathrm{E}-03$ & 0.210 & 0.437 & 0.353 & \\
\hline 1.32 & 0.78 & 1.74 & $5.077 \mathrm{E}-03$ & $3.000 \mathrm{E}-03$ & $6.692 \mathrm{E}-03$ & 0.239 & 0.438 & 0.323 & \\
\hline 2.47 & 0.74 & 1.69 & $9.500 \mathrm{E}-03$ & $2.846 \mathrm{E}-03$ & $6.500 \mathrm{E}-03$ & 0.202 & 0.441 & 0.357 & \\
\hline 5.169 & 0.734 & 1.68 & $1.988 \mathrm{E}-02$ & $2.823 \mathrm{E}-03$ & $6.462 \mathrm{E}-03$ & 0.175 & 0.435 & 0.390 & \\
\hline 11.75 & 0.64 & 1.55 & $4.519 \mathrm{E}-02$ & $2.453 \mathrm{E}-(03$ & $5.962 \mathrm{E}-03$ & 0.229 & 0.420 & 0.351 & \\
\hline 0.42 & 6.7 & 0.61 & $1.615 \mathrm{E}-03$ & $2.577 \mathrm{E}-() 2$ & $2.346 \mathrm{E}-() 3$ & 0.056 & 0.587 & 0.357 & T4 \\
\hline 0.71 & 4.4 & 0.356 & $2.731 \mathrm{E}-03$ & $1.692 \mathrm{E}-02$ & $1.369 \mathrm{E}-03$ & 0.090 & 0.552 & 0.358 & \\
\hline 1.38 & 3.86 & 0.244 & $5.308 \mathrm{E}-03$ & $1.485 \mathrm{E}-02$ & $9.385 \mathrm{E}-04$ & 0.092 & 0.556 & 0.352 & \\
\hline 2.94 & 2.85 & 0.22 & $1.131 \mathrm{E}-02$ & $1.096 \mathrm{E}-02$ & $8.462 \mathrm{E}-04$ & 0.161 & 0.520 & 0.319 & \\
\hline 5.1 & 2.55 & 0.169 & $1.962 \mathrm{E}-02$ & $9.808 \mathrm{E}-03$ & $6.500 \mathrm{E}-04$ & 0.154 & 0.524 & 0.322 & \\
\hline 9.1 & 2.27 & 0.167 & $3.500 \mathrm{E}-02$ & $8.731 \mathrm{E}-03$ & $6.423 \mathrm{E}-04$ & 0.186 & 0.478 & 0.336 & \\
\hline 14.34 & 1.95 & 0.158 & $5.515 \mathrm{E}-02$ & $7.500 \mathrm{E}-03$ & $6.077 \mathrm{E}-04$ & 0.216 & 0.464 & 0.321 & \\
\hline 0.75 & 0.46 & 7.36 & $2.885 \mathrm{E}-03$ & $1.769 \mathrm{E}-(03$ & $2.831 \mathrm{E}-02$ & 0.109 & 0.419 & 0.471 & Ts \\
\hline 1.16 & 0.39 & 4.78 & $4.462 \mathrm{E}-03$ & $1.500 \mathrm{E}-03$ & $1.838 \mathrm{E}-02$ & 0.125 & 0.432 & 0.443 & \\
\hline 2.2 & 0.37 & 4.64 & $8.462 \mathrm{E}-03$ & $1.423 \mathrm{E}-(03$ & $1.785 \mathrm{E}-02$ & 0.147 & 0.427 & 0.426 & \\
\hline 4.9 & 0.16 & 4.74 & $1.885 \mathrm{E}-02$ & $6.154 \mathrm{E}-04$ & $1.823 \mathrm{E}-() 2$ & 0.163 & 0.388 & 0.449 & \\
\hline 8.54 & 0.38 & 3.35 & $3.285 \mathrm{E}-02$ & $1.454 \mathrm{E}-03$ & $1.288 \mathrm{E}-02$ & 0.205 & 0.400 & 0.394 & \\
\hline 16.7 & 0.2 & 3.3 & $6.423 \mathrm{E}-02$ & $7.692 \mathrm{E}-(04$ & $1.269 \mathrm{E}-(02$ & 0.220 & 0.392 & 0.388 & \\
\hline 21.9 & 0.18 & 3.18 & $8.423 \mathrm{E}-02$ & $6.923 \mathrm{E}-04$ & $1.223 \mathrm{E}-(02$ & 0.231 & 0.369 & 0.399 & \\
\hline 0.21 & 2.16 & 1.81 & $8.077 \mathrm{E}-04$ & 8.308E-(03 & $6.962 \mathrm{E}-(03$ & 0.079 & 0.484 & 0.437 & T6 \\
\hline 0.51 & 1.6 & 1.44 & $1.962 \mathrm{E}-03$ & $6.154 \mathrm{E}-03$ & $5.538 \mathrm{E}-(03$ & 0.089 & 0.475 & 0.436 & \\
\hline 0.57 & 1.35 & 1.62 & $2.192 \mathrm{E}-03$ & $5.192 \mathrm{E}-(03$ & $6.231 \mathrm{E}-03$ & 0.088 & 0.485 & 0.427 & \\
\hline 1.13 & 1.13 & 0.96 & $4.346 \mathrm{E}-03$ & $4.346 \mathrm{E}-03$ & $3.692 E-(03$ & 0.144 & 0.461 & 0.395 & \\
\hline 2.5 & 1.16 & 0.95 & $9.615 \mathrm{E}-03$ & $4.462 \mathrm{E}-() 3$ & $3.654 \mathrm{E}-() 3$ & 0.151 & 0.462 & 0.387 & \\
\hline 5.75 & 1.42 & 0.95 & $2.212 \mathrm{E}-02$ & $5.462 \mathrm{E}-(03$ & $3.654 \mathrm{E}-(03$ & 0.166 & 0.470 & 0.363 & \\
\hline 9.9 & 1.16 & 0.87 & $3.808 \mathrm{E}-02$ & $4.462 \mathrm{E}-(03$ & $3.346 \mathrm{E}-03$ & 0.173 & 0.439 & 0.388 & \\
\hline 11.65 & 1.05 & 0.9 & 4.481E-02 & $4.038 \mathrm{E}-03$ & $3.462 \mathrm{E}-(03$ & 0.189 & 0.442 & 0.368 & \\
\hline
\end{tabular}

*Saturation trajectory 


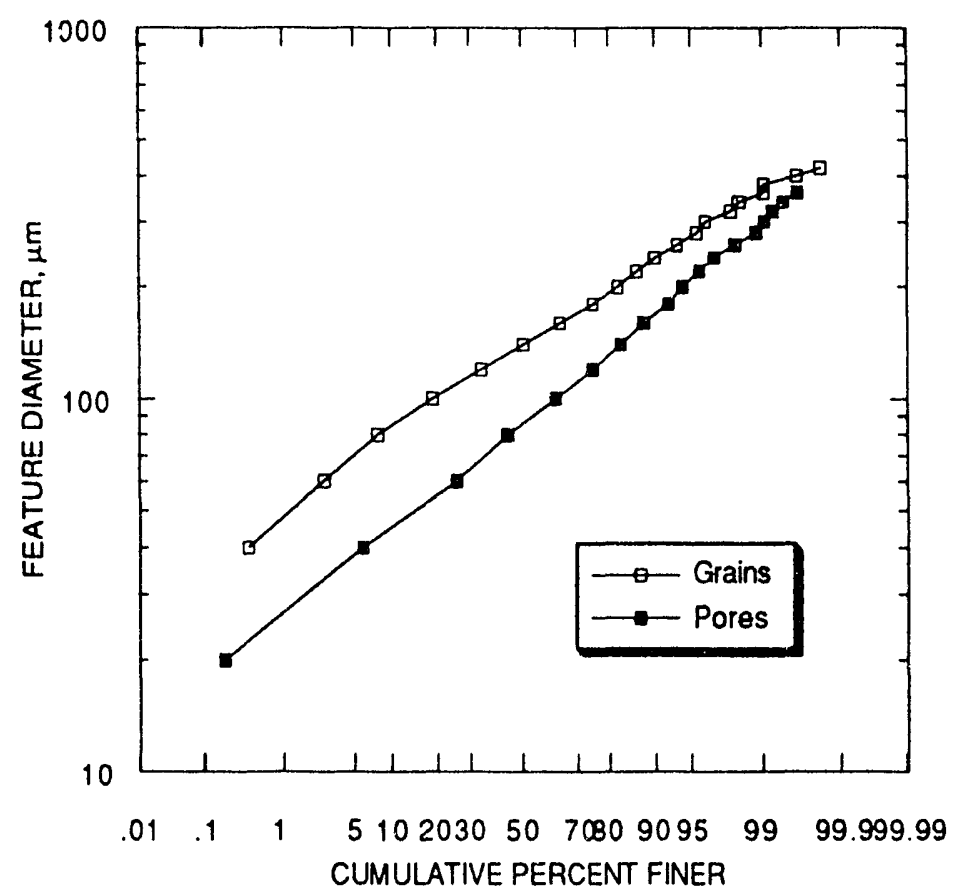

FIGURE 1. . Grain and pore dianneter distributions from thin-section analyses, fired $260 \cdot \mathrm{ml}$ ) Berea sandstone.

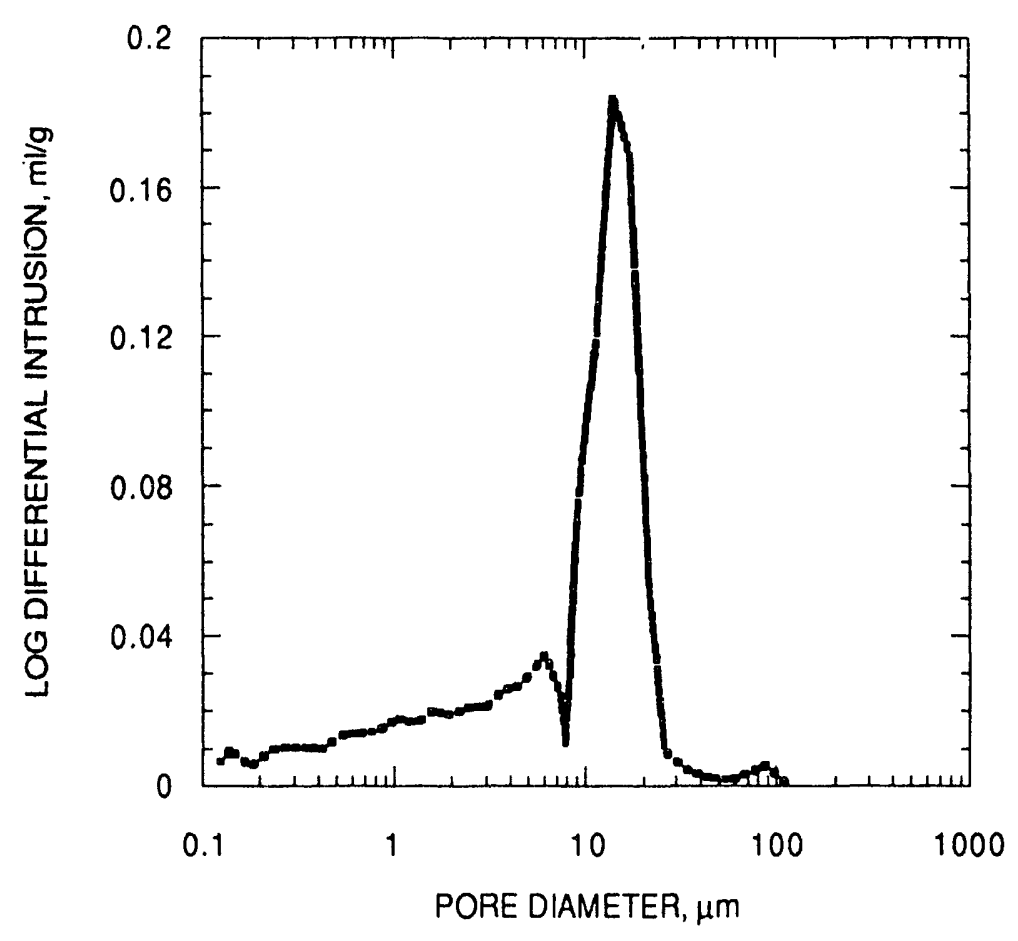

FIGURE 2. - Mercury intrusion porosimetry results, fired 260-mD Berea sandstone. 


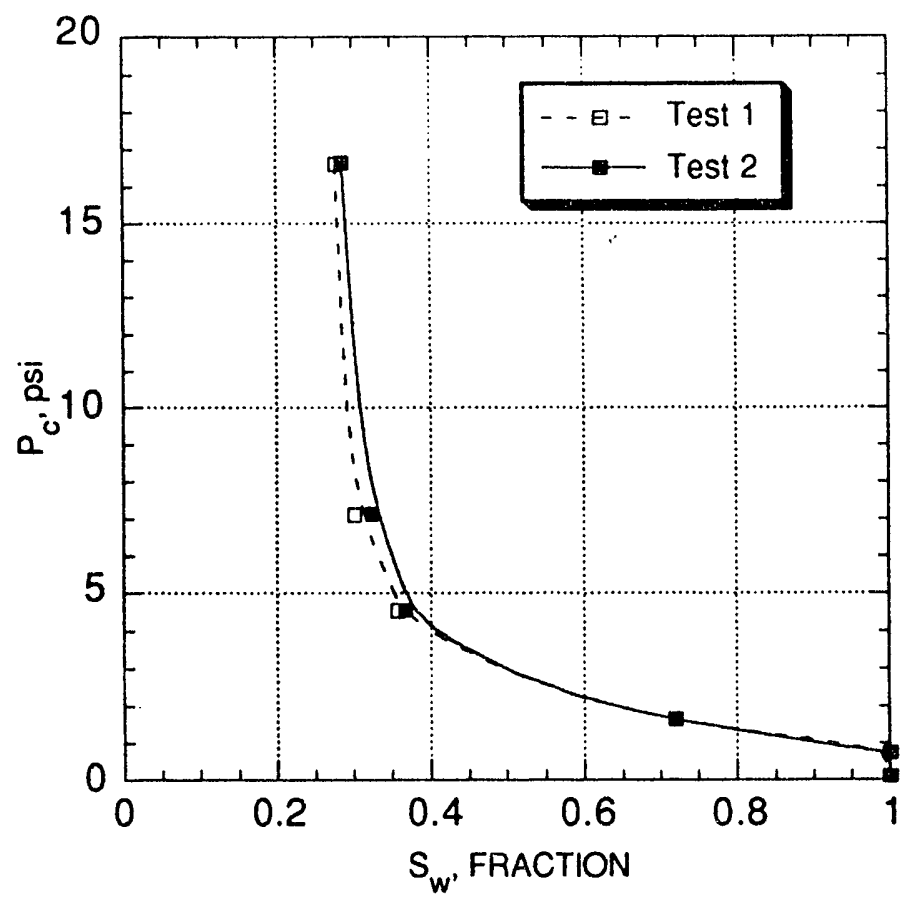

FIGURE 3. - Capillary pressure curves for two samples of 260-mD Berea.

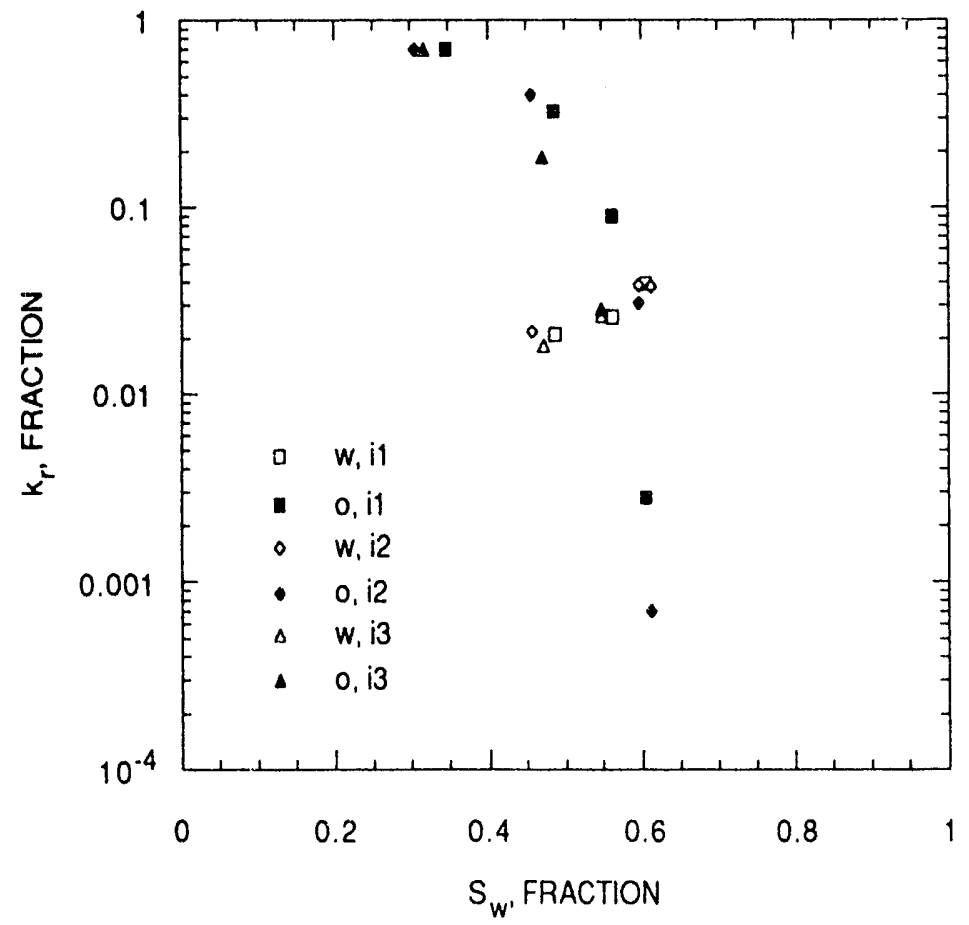

FIGURE 4. - Unsteady-state oil/water relative permeability results, fired Berea sandstone with 500 psig confining pressure. Data are normalized with respect to $k_{w}=157 \cdot \mathrm{mD}$ at $S_{w}=1.0$. 


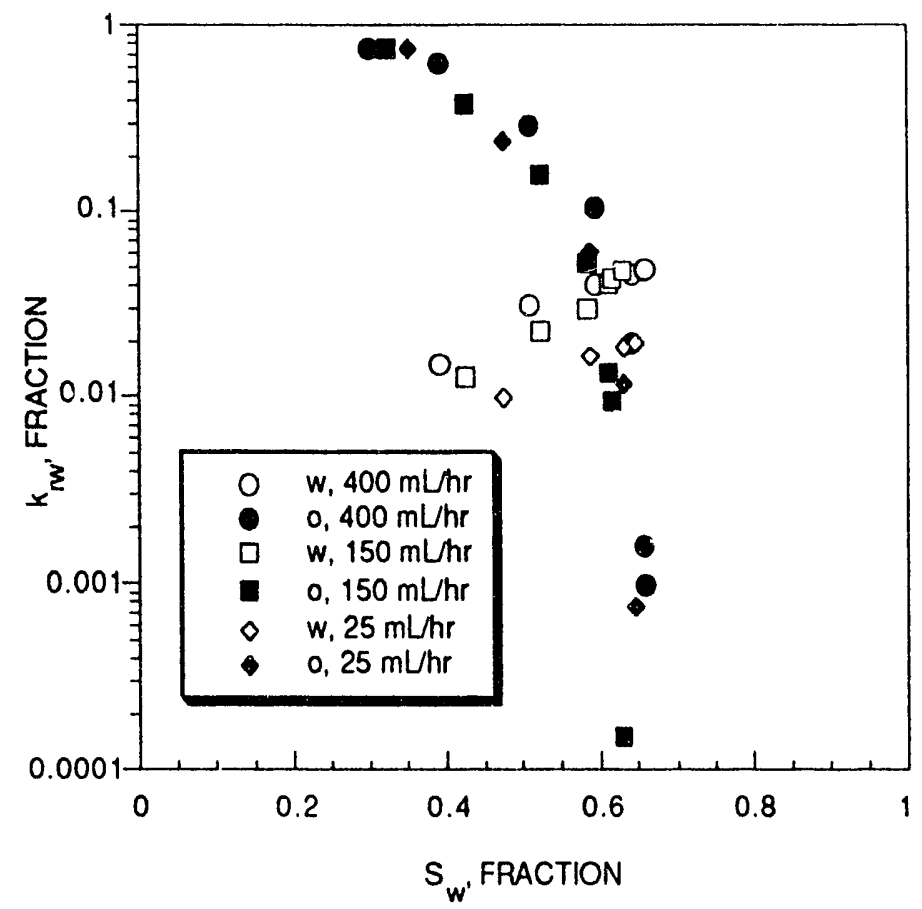

FIGURE 5. - Unsteady-state relative permeahility results for $260 \cdot \mathrm{ml}$ ) Berea sandstone with injection rates of 400,150 , and $25 \mathrm{ml} / \mathrm{hr}$. The confining pressure was $500 \mathrm{psig}$.

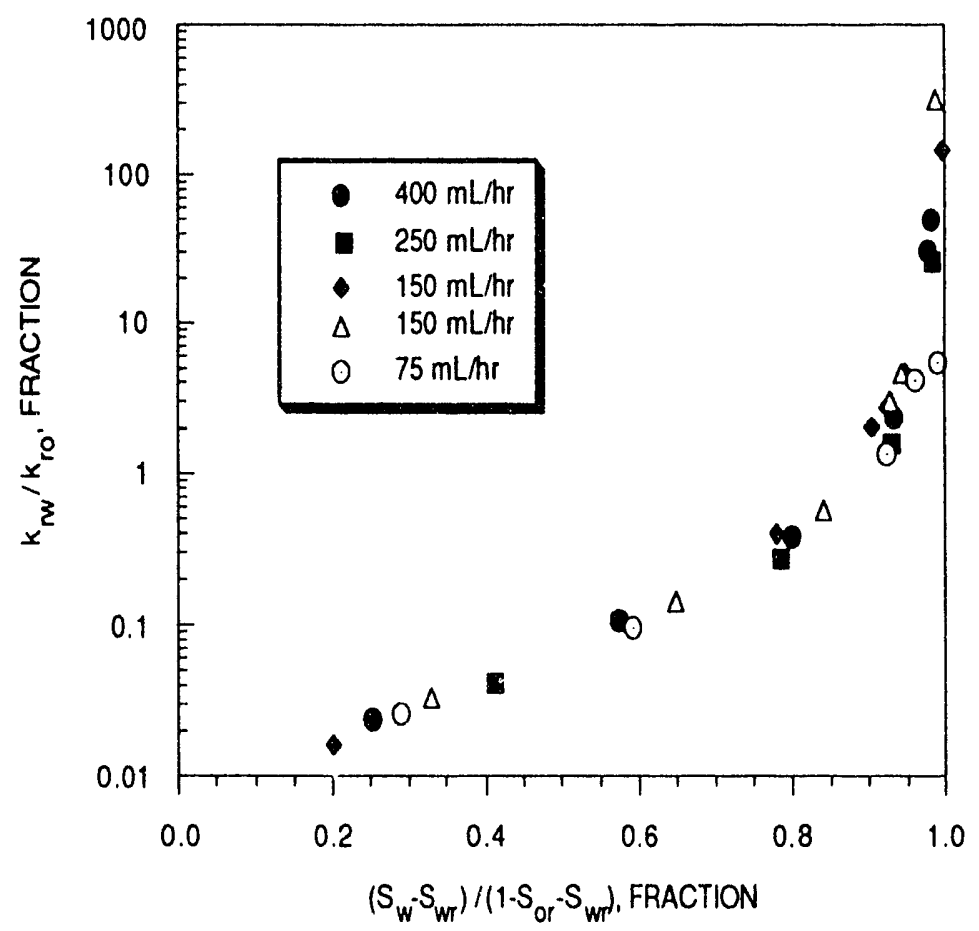

FIGURE 6. - Relative permeability ratio versus normalized saturation, 260-in D unsteady-state oil/water relative permeability test results. 


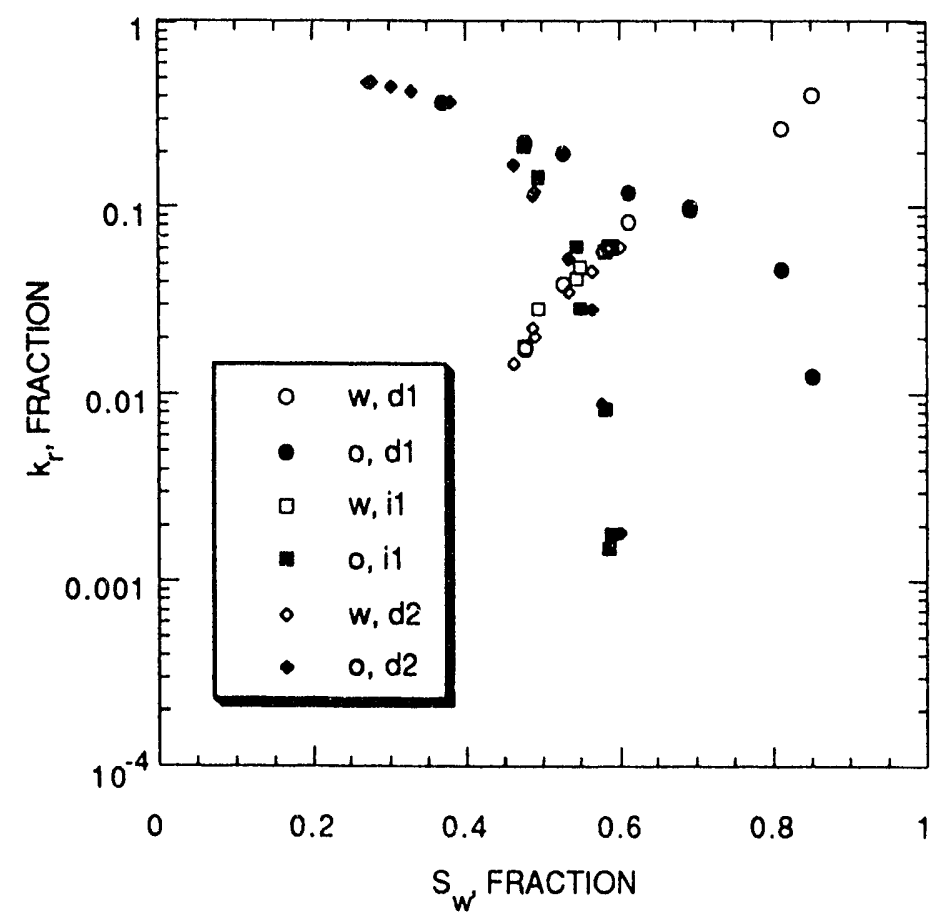

FIGURE 7. - Steady-e! nte oil/water relative permeability results, Bereis sandstone with 3,200 psig confining pressure. The data are normalized with respect to $k_{w}=2(00 \cdot \mathrm{ml})$ at $S_{w}=1.0$.

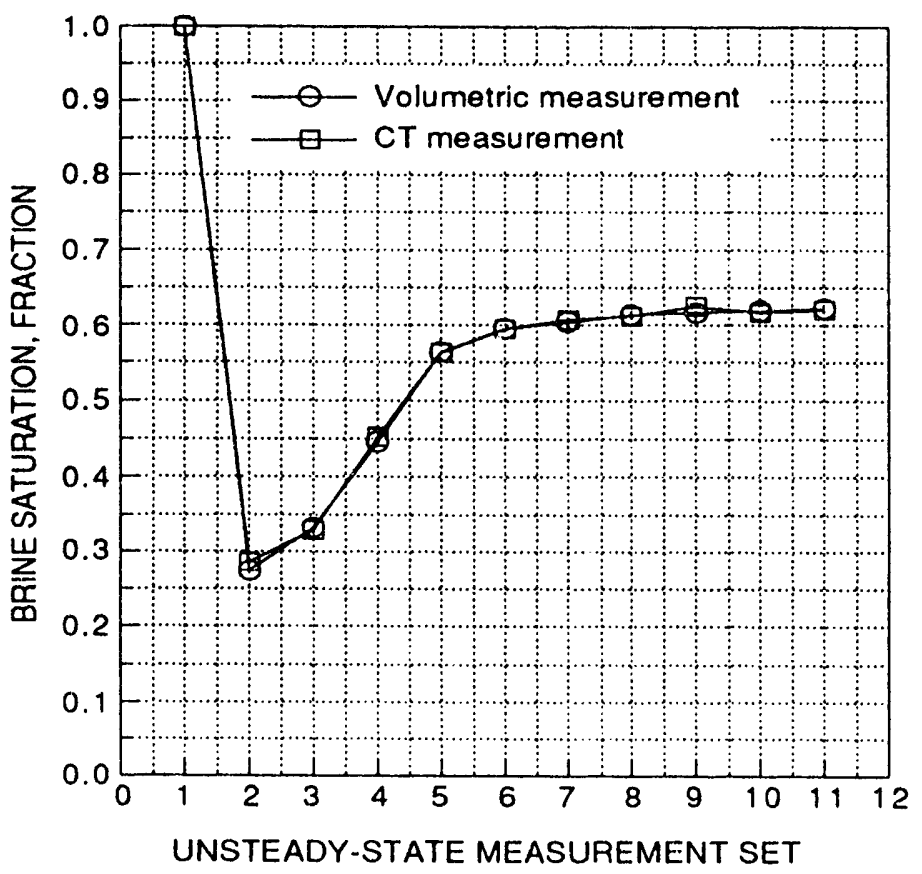

FICURE 8. - Comparison of brine saturations determined by volumetric and C"I techniçues during the waterllood test. 
A

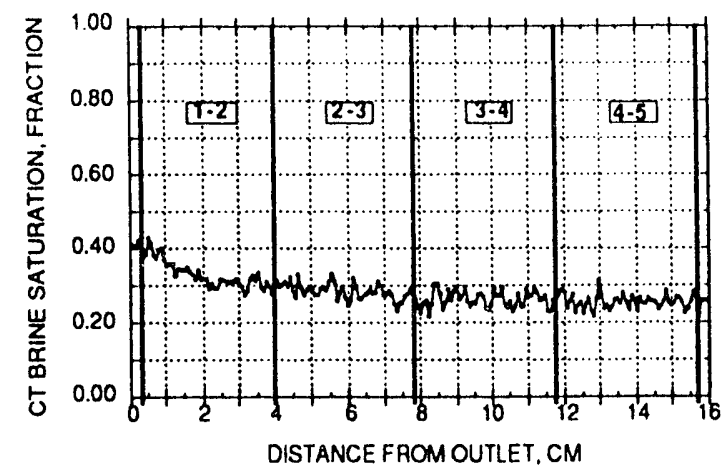

C

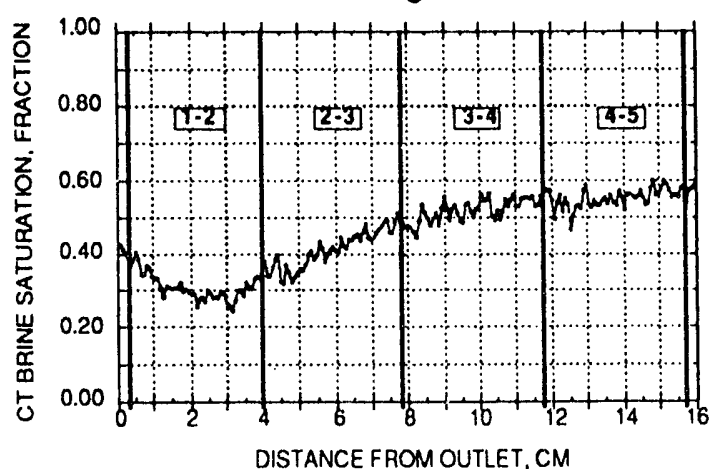

E

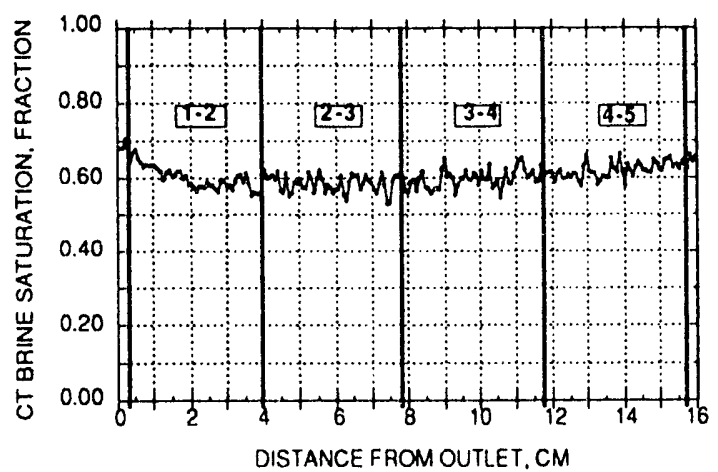

G

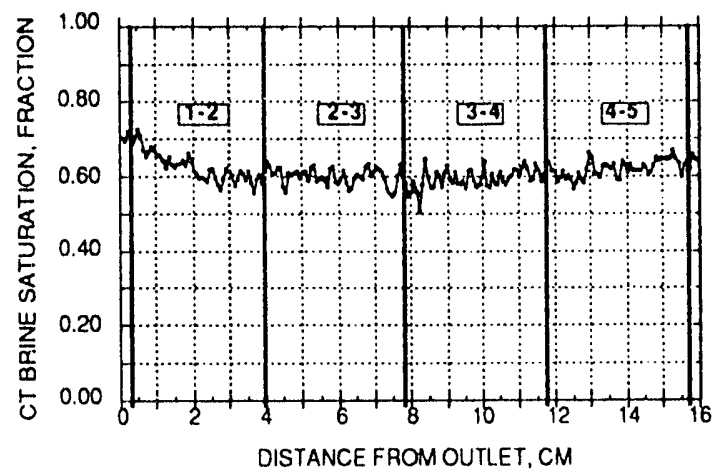

B

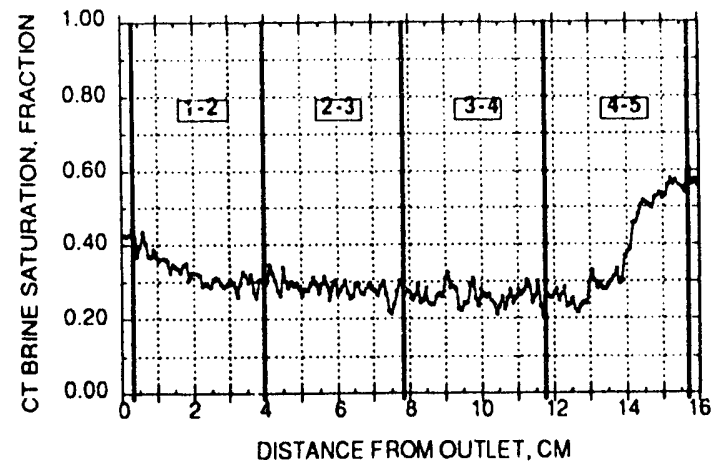

D

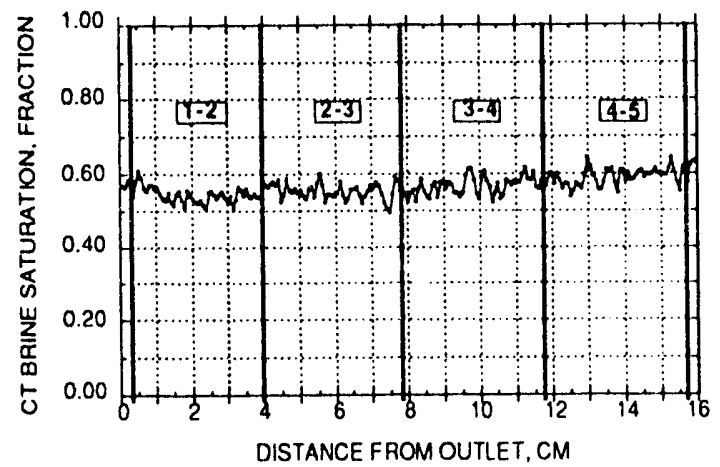

$F$

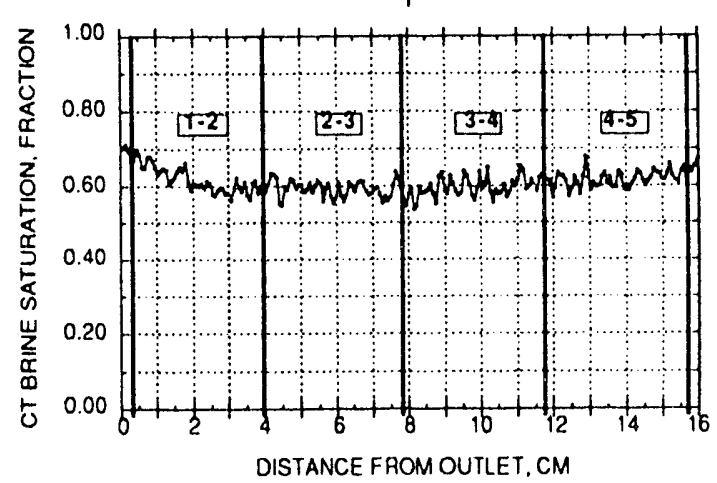

H

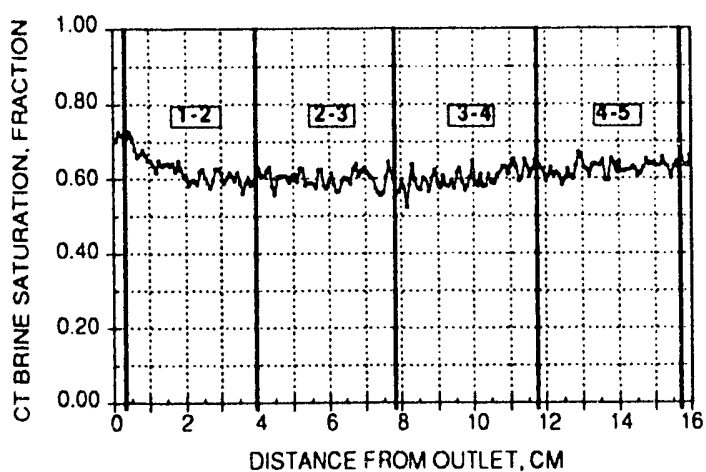

FIGURE 9. - Saturation distributions during the waterflowd test from Cr measurements. 'The heavy lines show the locations of the resistivity electrodes. 

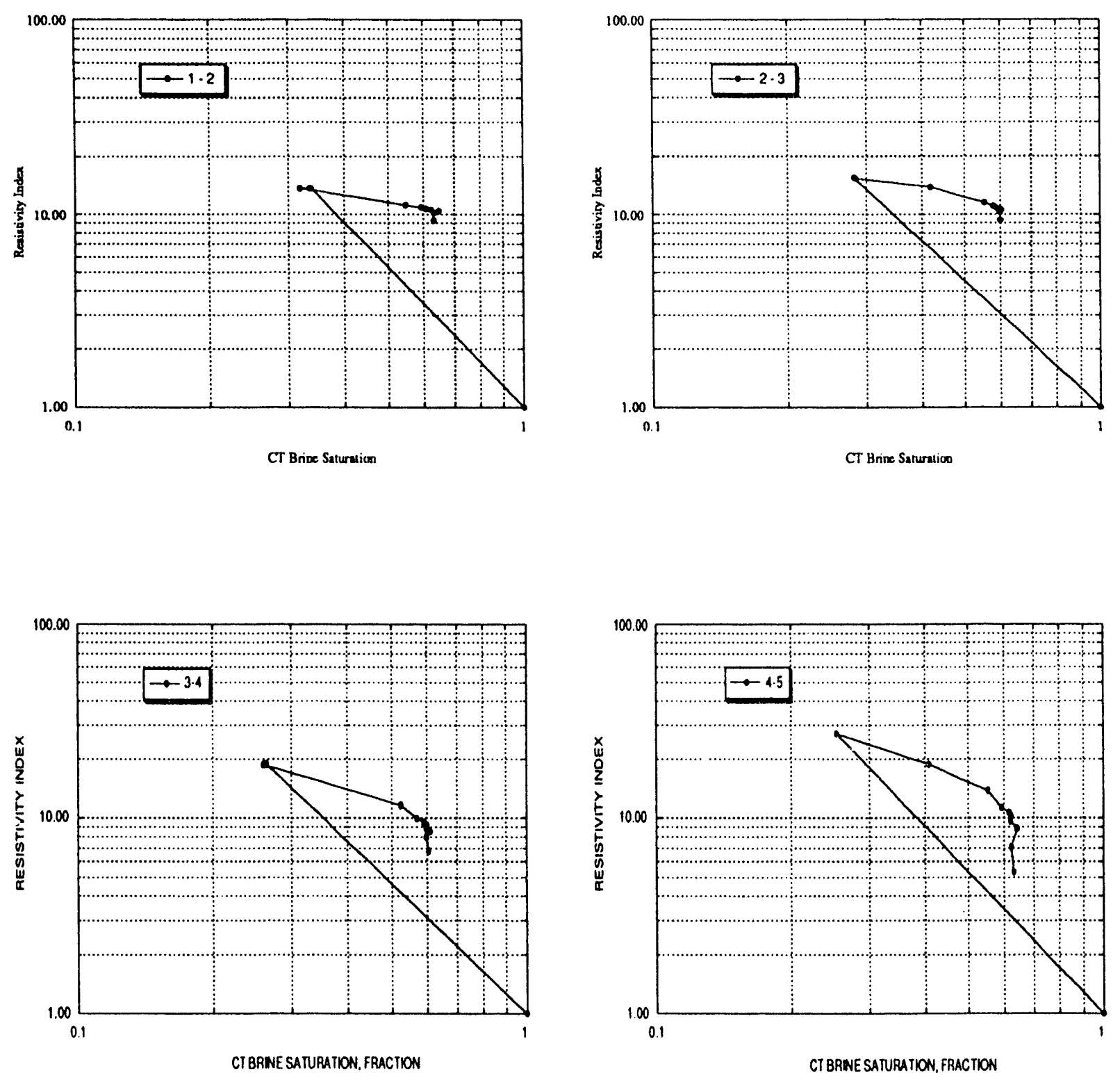

FIGURE 10. - Resistivity indices during the watertlond. 'The lines track the sequence of test measurements. 


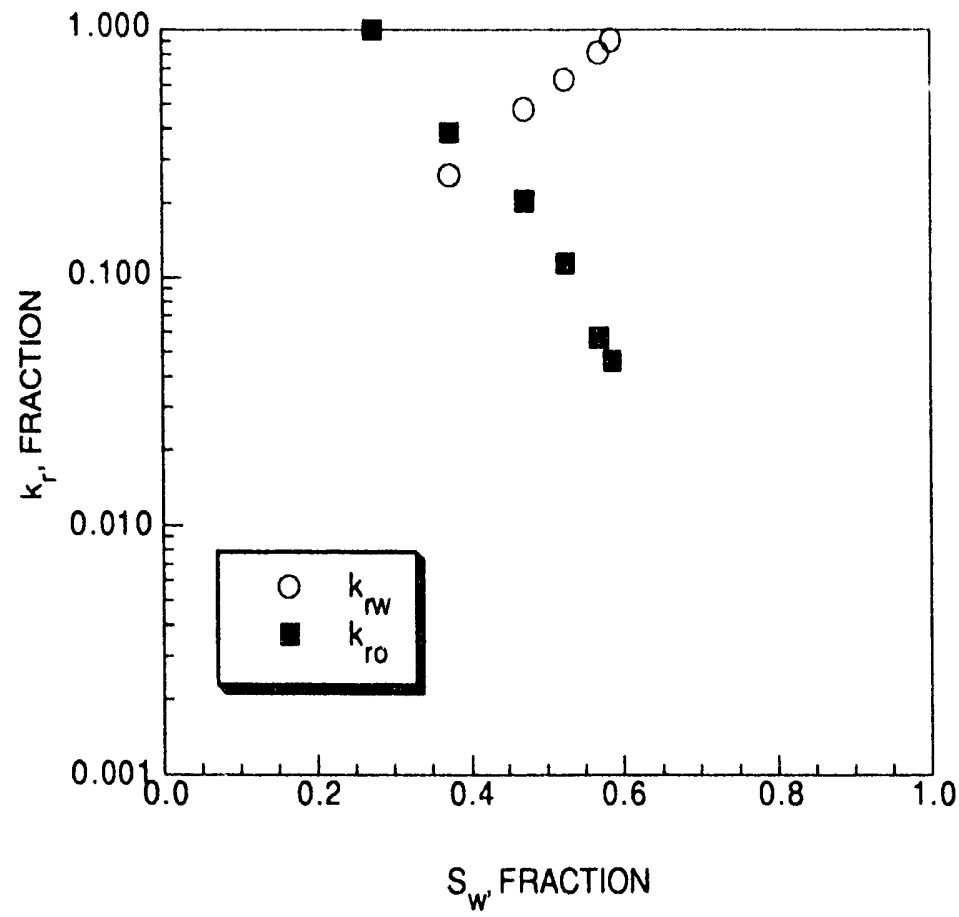

FIGURE 11. . Unsteady-state oil/water relative permeability results calculated from the C.T/waterflond huid procluction and pressure drop measurements.

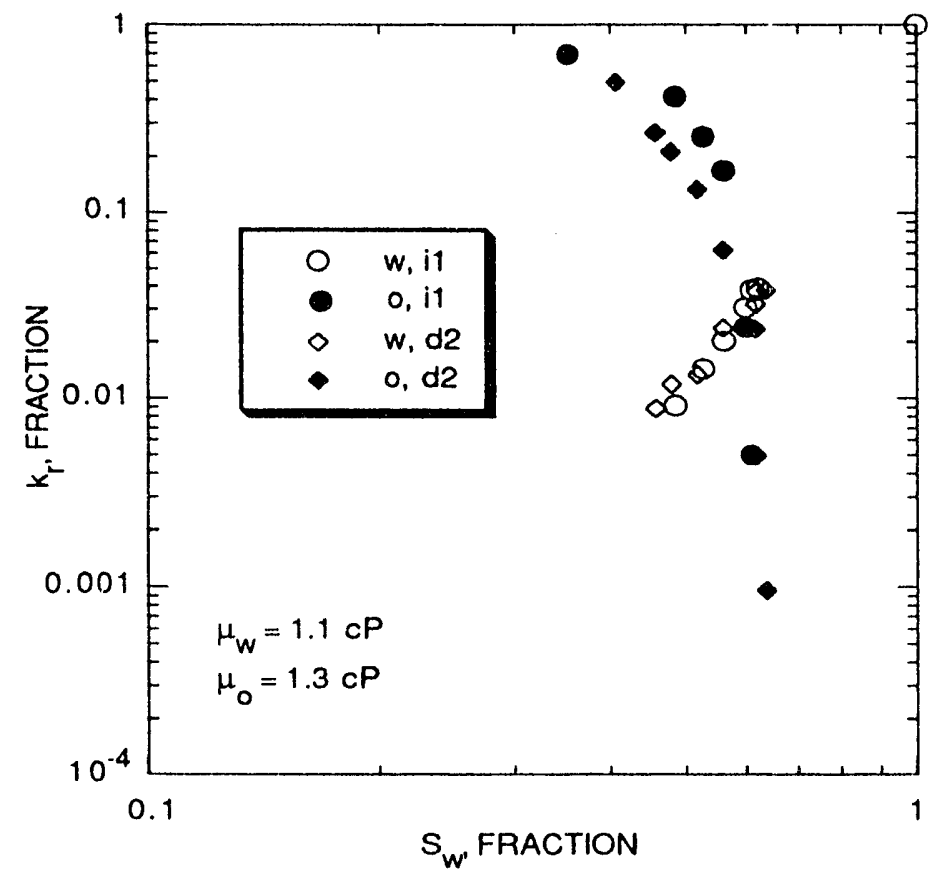

FIGURE 12. - Steady-state oil/brine relative permeahility results. Normalized with respect $\left.(1) k_{w}=2(0)-\mathrm{mI}\right)$ when $S_{w}=1.0$. 


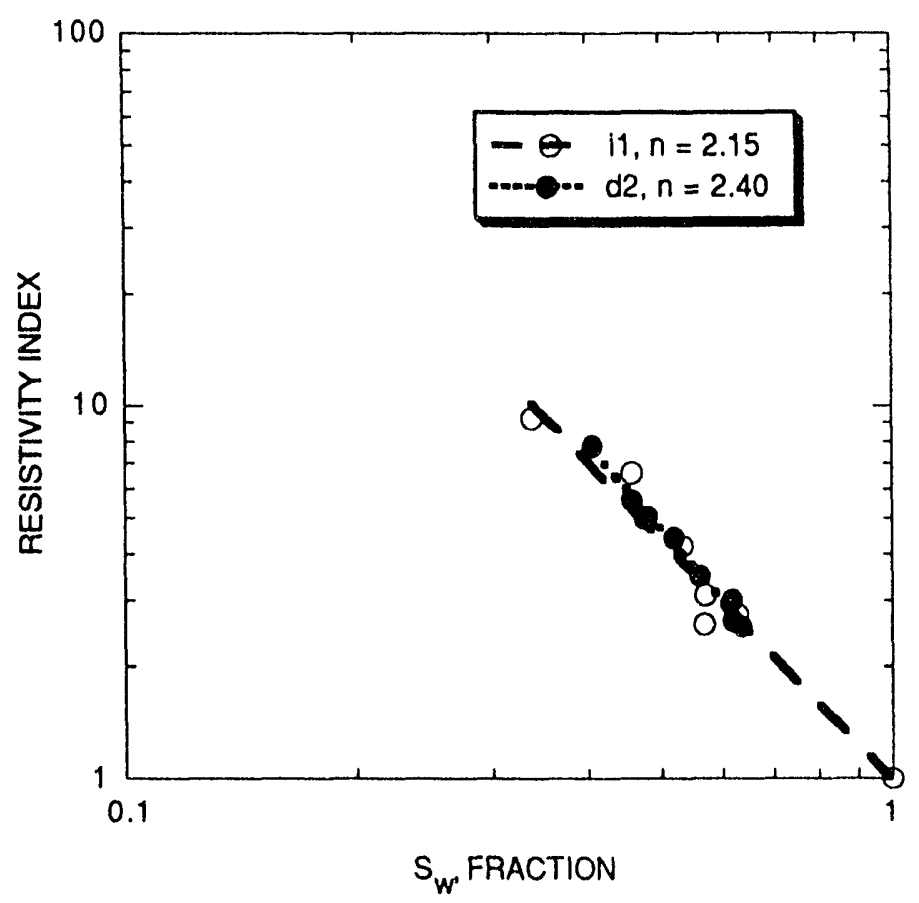

FIGURE, 13. - Resistivity results from the oil/brine steady-state test, $260 \mathrm{mD}$ Berea sandstone.

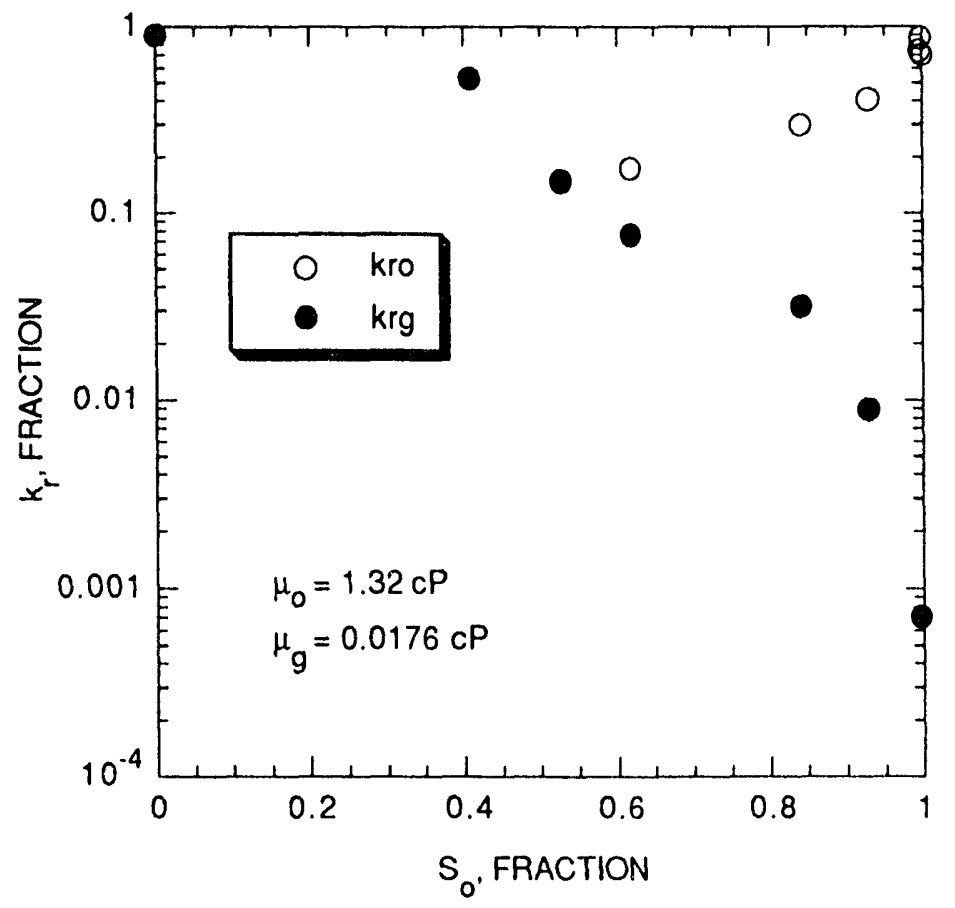

FIGURE 14. - Oil/gas relative permeability results. Normalized with respect $\left.\operatorname{lo} k_{w}=260 \cdot \mathrm{ml}\right)$ when $S_{w}=1.000$. 


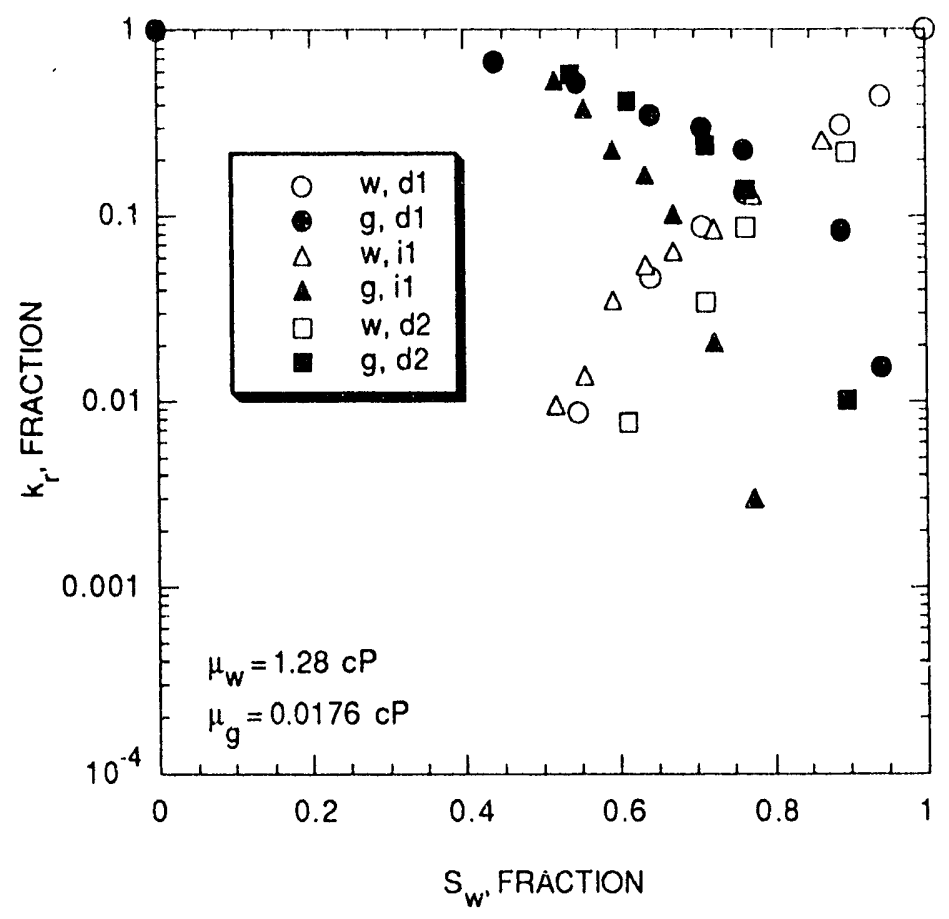

FIGURE 15. - (aas/water steady-state results. Normalized with respect to $k_{w}=2(00-\mathrm{ml})$ at $S_{w}=1.0$.

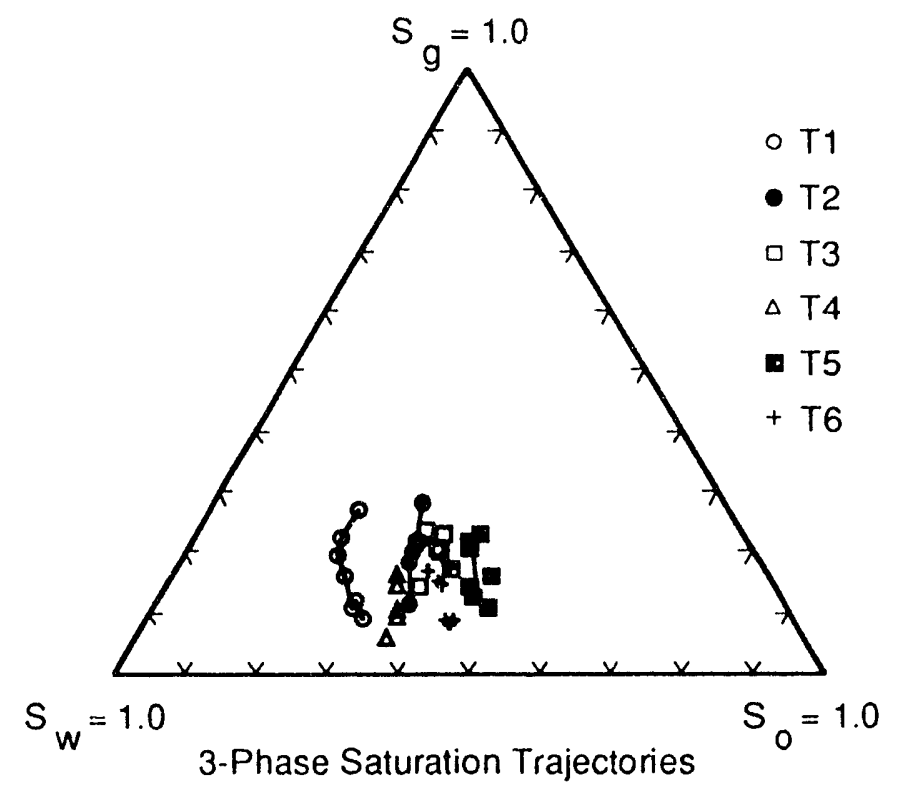

FIGURE 16. - DDI saturation trajectories during three-phase relative permeability measurements. 


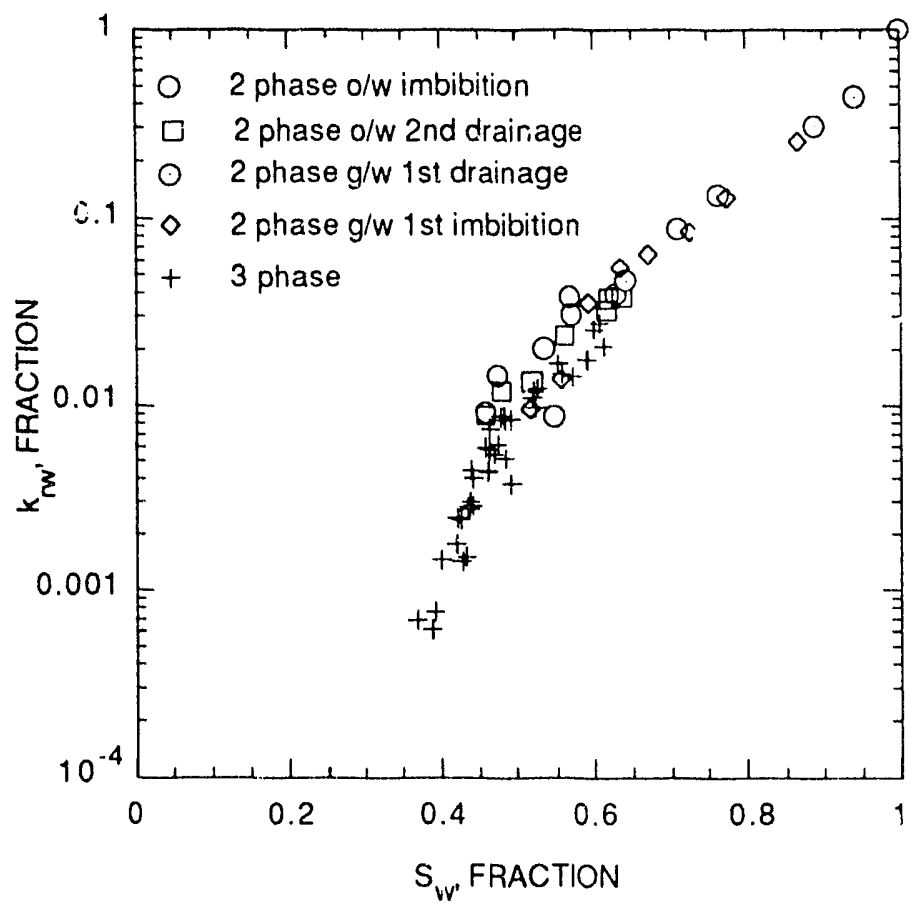

FIGURE 17. - Water relative permeability results from two- and three-phase meas:Irements. The data are normalized with respect to $k_{w}=260 \cdot \mathrm{mD}$ ) when $S_{w}=1.0$.

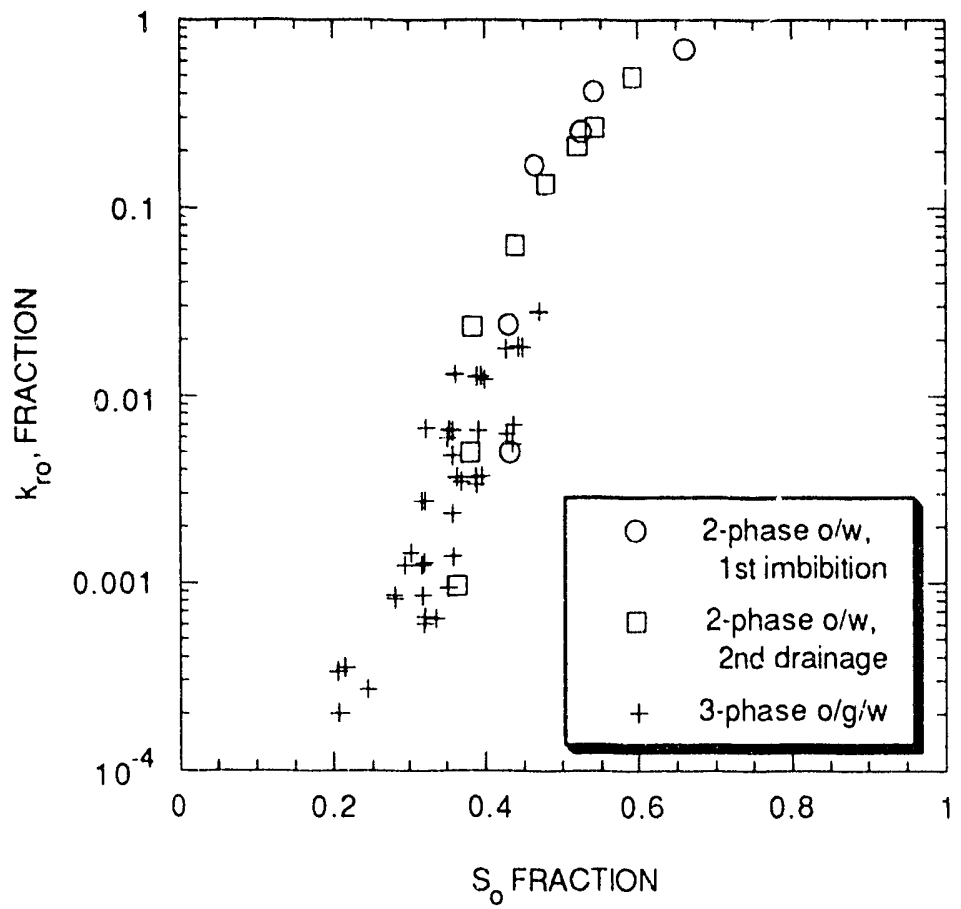

FIGURE: 18. - (Oil relative permeability results from two- and three-phase measurements. The data are normatized with respect to $\left.k_{w}=260-m 1\right)$ when $S_{w}=1.0$. 


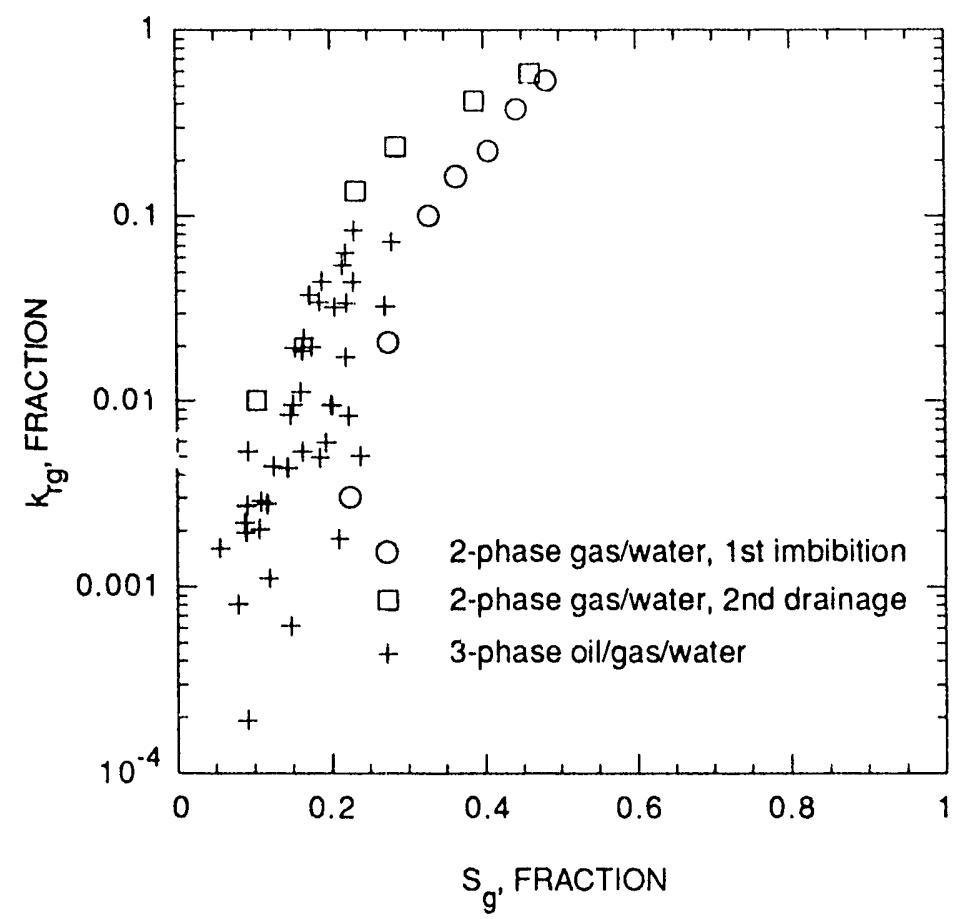

FIGURE 19. - Gas relative permeability results from two- and three-phase measurements. The data are normalized with respect to $k_{w}=260 \cdot \mathrm{mI}$ when $S_{w}=1.0$. 


\section{APPENDIX A}

\section{X-RAY AND MICROWAVE ATTENUATION TECHNIQUES FOR DETERMINING TWO- AND THREE-PHASE SATURATIONS}

During steady-statc tests, oil and water (brinc) saturation distributions are measured in situ by $\mathrm{X}$-ray and microwave attenuation techniques. For two-phase tests in which one of the fluid phases is water, the X-ray and microwave results are directly comparabic and gencrally agrec to within 3 saturation units (or to within 0.03 on a saturation scalc from 0 to 1.0).

To conduct a scan, the X-ray or microwave instrument is advanced to the outlet face of the rock sample. An X-ray or microwave beam of $1 \mathrm{~cm}$ diamcter (approx.) is directed at the center of the sample. The decrease in X-ray or microwave intensity is measured as the beam passes through the rock. After recording the measurements, the scanner is advanced $7 \mathrm{~mm}$ to the next scan position. Similar measurements are recorded until the instrument reaches the outlet face of the sample. The X-ray and microwave scans provide attenuation data representative of a plane through the ecnter of the sample from the inlet to the outlet. Saturation distributions are calculated by the techniques described in the following paragraphs. The pressure taps that are used for $\Delta \mathrm{P}$ mcasurements during the tests on plastic-encased rocks are spaced at lcast $2.5 \mathrm{~cm}$ away from the inlet and outlet faces of the rock so that capillary end effects do not influence the permeability measurements. The saturations between the pressure taps are averaged and these averages are plotted against relative permcabilitics on the relative permeability graphs. Unique microwave and X-ray calibrations are determined for cach rock and fluid system at the start of cach test.

Figure A-1 shows a typical microwave calibration curve in which the natural log of the incident microwave power (a) divided by the emergent microwave power (b) is plotted against water saturation. The attenuation of the microwave signal is principally governed by the amount of water in the sample and calibrations are almost identical whether the second phase is oil or gas. For this reason, the microwave scanner is an excellent tool for measuring brinc saturations during both two- and threc-phase tests as long as the containment system does not reflect or absorb microwaves. Our low-power microwave klystron does not excite the water molecules sufficiently to cause a measurable increase in the temperature of the fluid system.

Figure A-2 shows typical X-ray calibrations in which the natural $\log$ of the emergent $X$-ray intensity $\{\operatorname{Ln}(I)\}$ is plotted against oil saturation. In our system, the incident $\mathrm{X}$-ray intensity is assumed $\mathrm{t}(\mathrm{O}$ remain constant and gencrally does, except immediately before the tube or some other component within the $X$-ray circuitry fails, causing an abnormal decrease in the emergent $X$-raly attenuation. Two callibrations are shown; one for an oil/water system and a sccond for an oil/gas systcm. A third calibration, which is not shown, can be constructed to calculate water satturations from X-ray measurements in a gas/water system. The calibrations are dependent on the volumes of each fluid present in the system. For a test in which only two fluid phases are present in the rock, the appropriate calibration is used to calculate the fluid saturations within the rock. In a threc-phase system, water saturations are determined from microwave results while the oil saturation is determined by:

$$
\left.S_{0}=\left(S_{0}\right)_{o w}+\left(1-\frac{S_{w}}{1-\left(S_{0}\right)_{o w}}\right) \mid\left(S_{0}\right)_{o w}-\left(S_{o}\right)_{o g}\right](A-1)
$$

Where $S_{O}$ is the oil saturation, $S_{W}$ is the water saturation from microwave results, $\left(S_{O}\right)_{0 w}$ is the oil saturation calculated from the oil/water calibration equation, and $\left(\mathrm{S}_{\mathrm{O}}\right)_{\mathrm{Og}}$ is the oil saturation calculated from the oil/gas calibration equation. The plane defined by the two lines on Fig. A-2 describes the combinations of $\mathrm{X}$-ray scan results and oil saturations that may occur during a threc-phase test. The slopes of the calibration lines depend upon the amount of X-ray tagging agent that is added to one of the fluid phases. Figure A-2 results are for a refined oil tagged with $10 \%$ by wcight iodododecanc. A higher tag concentration yiclds a lower $\operatorname{Ln}(\mathrm{I})$ value for the oil saturated rock, increasing the resolution of the saturation measurement.

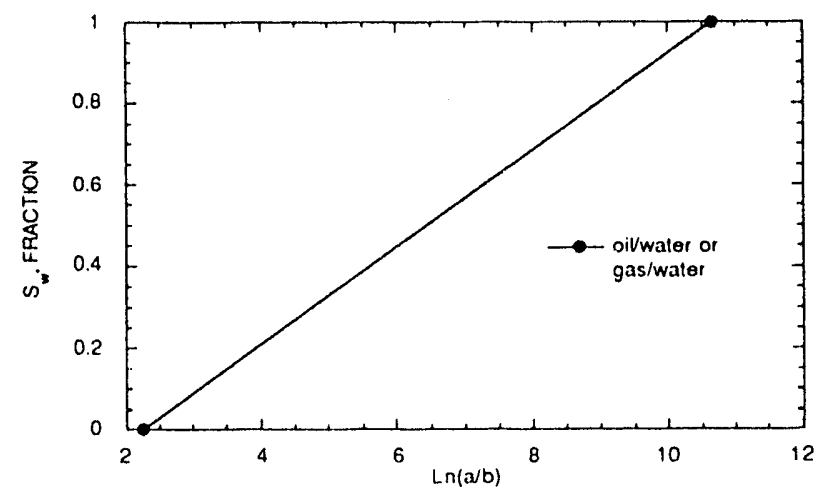

FIGURE $\Lambda$-1. - Typical microwave calibration for one position within the rock sample. 


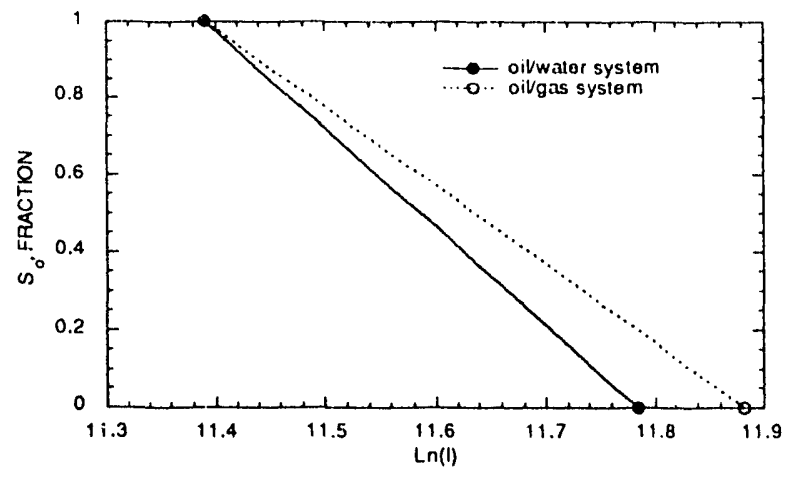

FIGURE A.2. - Typical oil saturation calibrations for one position within the rock sample.
For many tests, it is not desirable to completcly saturatc the rock with oil when generating $X$-ray calibration data. One method that we use to completely calibrate the $X$-ray is to scan the dry rock, then scan the brine saturated rock, and finally scan the rock when saturated with a brine that contains a tagging agent which identically matches the lincar attenuation characteristics of the oil phase. The tagged brine can be flushed out of the system, leaving the rock completely saturated with brine and ready for the relative permeability test. 


\section{APPENDIX B \\ DUAL ENERGY X-RAY TECHNIQUES FOR MONITORING THREE- PHASE SATURATIONS}

The current practice in the NIPER relative permeability laboratory is to use both X-ray and microwave scanners for three-phase saturation detcrminations. A litcrature study and evaluation of X-ray characteristics of matcrials were conducted during the project year to determine if the NIPER $X$-ray scanner could be operated in the 'dual energy ' mode, providing an additional check on the accuracy of the saturation measurements. The technique requires tagging both the brine and oil phases with $X$-ray tags of different attenuation charactcristics.

\section{Background}

From chapter 2 of ref. 1, if a perfectly collincar monochromatic $x$-ray beam of intensity $I_{O}$ is directed at an absorber of thickness $t$ and density $\rho$ and $X$-ray masks are placed on both sides of the absorber, the emergent beam has an intensity $\mathrm{I}$, which is less than $\mathrm{I}_{\mathrm{O}}$ because of the absorption or attenuation of the $\mathrm{X}$-rays in passing through the absorber. The emergent intensity is given by:

$$
\mathrm{d} I / I=-\mu \mathrm{dt}
$$

where $\mu$ is the lincar absorption cocfficicnt $\left(\mathrm{cm}^{-1}\right)$ and the negative sign indicates that the intensity decreases upon passing through matter. Assuming $\mu$ is independent of thickness $\mathrm{t}(\mathrm{cm})$ yiclds the Lambert law:

$$
\mathrm{I}=\mathrm{I}_{\mathrm{O}} \mathrm{c}(-\mu \mathrm{t})
$$

Two of the morc uscful X-ray absorption cocfficients are the lincar absorption coefficient $\mu$ and the mass absorption cocfficient $\mu_{m}$, which equals $\mu / p$. Tables of $\mu_{\mathrm{m}}$ versus $X$ ray wavelength can be found in the litcraturc. Taking advantage of the relationship between $X$-ray wavelength (w) and excitation potential $(\mathrm{V}, \mathrm{KV})$

$$
w=12.396 / \mathrm{V}
$$

allows onc to calculate mass attenuation cocflicients for various elements at different $X$-ray potentials.

Attenuation cocfficients generally increase with decreasing wavelength. However, abrupt discontinuitics known as absorption celges or critical absorption wavelengths occur which are significant. The best lags for $X$-ray saturation determination are matcrials containing an clement for which a critical absorption edge occurs at a wavelength that is slightly longer than that of the test. The mass absorption coefficicnt for a mixture of elements can be calculated by

$$
(\mu / \rho)_{A B}=\left(\mu_{m}\right)_{A B}=W_{A}(\mu / \rho)_{A}+W_{B}(\mu / \rho)_{B}
$$

where $W_{A}$ is weight fraction $A$. Then the attenuation caused by a thickness of a mixture of elements can then be found from

$$
I=I_{O} c^{\left[-\left(\mu_{m}\right)\right.} A^{\left.\left(\rho_{A B}\right) t\right]}
$$

if the density of the mixture is known. Otherwise, the attenuation can be calculated from

$$
\left.I=I_{O} c-\left(\mu_{m}\right)_{A}\left(\rho_{A}\right) t_{A}\right]\left\{e^{\left.l-\left(\mu_{m}\right)_{B}\left(\rho_{B}\right) t_{B} l\right\}}\right.
$$

A number of other factors influence $X$-ray attenuation, such as the distances between the X-ray source, absorber, and detcetor, type of detector used, and polychromatic nature of the X-ray beam. Because of these factors, one should consider that in practice, $X$-ray attenuation results will be somewhat different from calculations or predicted results using Eq. B-6.

\section{Dual Energy Technique}

Laird and Putnam ${ }^{2}$ described a technique for determining threc-phasc salurations using cadmium chloride as an X-ray lag for the brine phase and iodobenzene as the X-ray tag for the oil phase in an oil-brinc-gas threc-phase system. A study was conducted to cvaluatc less hazardous tags. Mass altenuation cocfficients for a number of candidate X-ray tags were calculated for a number of common tag/fluid combinations using Eq. B.4 and $\mathrm{K}$ spectrum data from appendix 7A from ref. 1 and from fluid densitics measured in the laboratory. Potentials were calculated from wavelengths in appendix 7A of ref. 1 and using equation B3. The results indicated that potassium bromide and iododecane might be adequate for tagging the brine and oil phases in a threc-phase system. The potassium bromide and iododecane tag concentrations can be selected such that the two fluids will have identical attenuation characteristics at one X-ray energy and different attenuation characteristics at a second energy. Table B-1 shows calculated linear 
attenuation characteristics for nitrogen gas, $3.406 \%$ by weight $\mathrm{KBr}$ in water, and $16 \%$ by weight iododecane in decane at potentials of $24.792 \mathrm{KV}(25 \mathrm{KV}$ is the lower limit on the NIPER machine) and $41.320 \mathrm{KV}$ at ambient conditions.

Note that the linear attenuation cocflicient for nitrogen gas is very low but non-zcro. As the lincar attenuation coefficient is sensitive to density, changes in temperature and pressure that affect the fluid densitics will also affect their linear attenuation coefficients.

The X-ray results at both potentials werc calculated assuming various threc-phase saturation conditions. For simplicity, equation B-6 was rewritten as

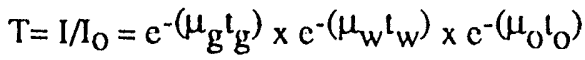

where $T$ is the transmission factor (adopted from Laird and Putnam) and subscripts $g, w$, and o denote gas water and oil. Assuming that the $\mathrm{X}$-ray bcam passes through a unit thickness containing gas, oil, and water, transmission factors for various saturation conditions were calculated by assuming that each phase could be modeled as a thickness of fluid. Calculations were found to be simplified when - $\operatorname{Ln}(\mathrm{T})$ was used rather than T. Figure B-1 graphically shows some of the results at $24.79 \mathrm{KV}$ and $41.32 \mathrm{KV}$ potentials. Since the attenuation characteristics of the water and oil phases were made equal at the $24.79 \mathrm{KV}$ potential, the gas saturation can be casily calculated at the $24.79 \mathrm{KV}$ condition regardless of oil and water saturation. Once the gas saturation is known, the oil and water saturations can be calculated from the $41.32 \mathrm{KV}$ results.

This evaluation of dual energy $X$-ray techniques indicates that the lincar $X$-ray scanner in the NIPER relative permeability lab may be sufficient to lake advantage of this technology to improve the accuracy and reliability of the three-phase saturation measurements if X-ray scans can be taken at two energy levels on both sides of the iodine $K$ absorption edge.

In the previous example, the $X$-ray voltage scuings of 24.7 and $41.3 \mathrm{KV}$ were selected to provide intensity measurcments on either side of the iodine $\mathrm{K}$ absorption edge which occurs with an excitation potential of $33.2 \mathrm{KV}$. Additional calculations werc performed to cvaluatc the suitability of using the technique for potentials above the $\mathrm{K}$ absorption edges of the fluids. The calculations assumed

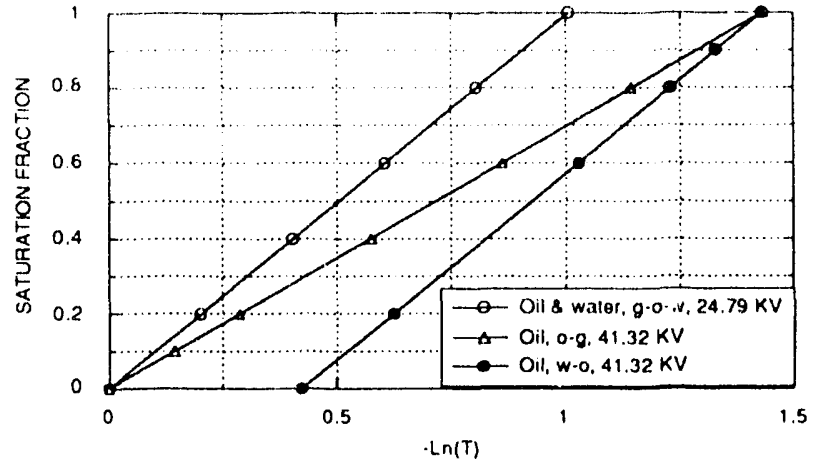

FICURE B-1. - Saturation fraction versus - In(T) from example calculations.

that the oil phase consisted of decane tagged with iododecane while the brine phase consisted of $\mathrm{KBr}$ in water. Lincar attenuation coefficients were calculated for the two Mluids for potentials of 50 and $55 \mathrm{KV}$. The results are shown in Fig.B-2.

Assume that the two fluids are lagged to have lincar attenuation cocfficients equal to $0.5 \mathrm{~cm}^{-1}$ at the $50 \mathrm{KV}$ potential. To achicve this condition, the oil phase is tagged with $8 \%$ by weight iododecane while the brine phase is tagged with $10 \% \mathrm{KBr}$. When the potential is stepped up to $55 \mathrm{KV}$, the oil phase linear attenuation coefficient is approximately 0.3 . The brine phase linear attenuation coefficient is also about 0.3. As the attenuation coefficients for the two fluids are nearly identical at both $\mathrm{X}$-ray potential scltings, the tagging arrangement would not be very useful for measuring fluid saturations during threc-phase tests. Revicwing the results of Fig. B-2, for practically any $\mathrm{KBr} / \mathrm{brinc}$ and iododecane/decane system in which the brine and oil phases are tagged to have similar $X$-ray attenuation cocfficients at the 5) KV potential, the lincar attenuation cocfficients for the two fluids are also similar at the $55 \mathrm{KV}$ potential. The best contrast in the attenuation characteristics of the two lagged fluids occurs when the $X$-ray operating potentials are within 5 to $10 \mathrm{KV}$ on either side of a prominent absorption cdge for one of the two lluids.

TABLE B-1. - Calculated linear attenuation coefficients at two potentials

lincar attenuation coefficient, $\mu, \mathrm{cm}^{-1}$

\begin{tabular}{llcc} 
Potential, KV & Nitrogen & $\mathbf{3 . 4 0 6 \% \mathrm { KBr } \text { in water }}$ & 16\% indodecane in decane \\
\hline 24.792 & $5.000 \times 10^{-4}$ & 1.006 & 1.006 \\
41.320 & $2.500 \times 10^{-4}$ & 0.422 & 1.433 \\
\hline
\end{tabular}




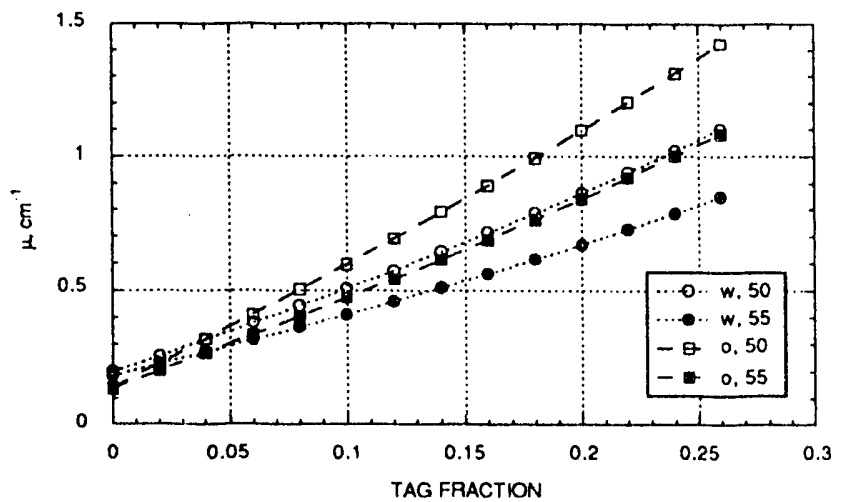

FIGURE B-2. - Linear X-ray attenuation coefficients for brine tagged with $\mathrm{KBr}(w)$ and decane tagged with iododecane at potentials of 50 and $55 \mathrm{KV}$.

\section{References}

1. Bertin IE. Principles and Practice of X-Ray Spectrometric Analysis. Second lidition. Plonum Press, New York, 1975.

2. Laird, A. and J. Putnam. Threc-Component Saturation in Porous Media by X-ray Techniques. Petrolewn Transactions, AIME, Vol. 216,1959 . pp. $216 \cdot 220$. 


\section{APPENDIX C}

\section{USING A WEIGHT METHOD FOR FLUID PRODUCTION MEASUREMENTS DURING UNSTEADY-STATE TESTS}

The manner in which brine and oil production versus time data are recorded during an unstcady-statc relative permeability test affects the accuracy of the results. Typical test measurements are obtained by recording the pressure drop across the length of the sample, and oil and brine volumes collected in a scrics of graduated collection flasks at several times during the test. Obtaining a number of good measurements immediatcly after water brcalkthough is critical and often very difficult depending on the nature of the test. Recording the fluid volumes in collection tubes can be tedious, cspecially when the brine and oil do not readily scparate.

An automated method of recording fluid production volumes during unsteady-state tests is requircd. Onc choice would be to use a separator which is available on the market. The separator consists of two compartments: one in which the fluids enter and another connected compartment in which the position of the oif-watcr interface is established by a sonic technique. An alternative method for tests that do not require backpressure is to take advantage of the difference in fluid densities to monitor production. This report describes a system designed in our laboratory to continuously measure the cumulative weight of oil and cumulative weight of brine produced during an unsteady-state test. Fluid volumes are then calculated from the weight measurements. The system is well suited for oil/brine systems that exit the rock in the form of an emulsion since the oil and brine in the oil collection vessel do not have to be well segregated in order to calculate the produced fluid volumes.

\section{Principle of Operation}

Figure $\mathrm{C}-1$ shows the proposed method for automating unstcady-state volume measurcments. The apparatus consists of two collection vessels, $U 1$ and $U 2$. U1 is a closed vessel, initially filled completely with brinc, with an inlet from which test fluids enter and an outlct from which one drop of brine flows for cvery drop of brinc or oil that enter U1. Each drop of brine that Icaves U1 is captured in U2. A film of oil on the surface of brinc in U2 prevents the brine in U2 from evaporating. As long as the densities of the brine and oil test fluids are constant and the load cells used for weight measurements are accurate, the produced fluid volumes can be calculated at any time during the test from the change in $U 1$ and $U 2$ wcights as described in the following calculations.
$\mathrm{V}_{\mathrm{O}}=$ oil volume, $\mathrm{cm}^{3}$

$\mathrm{V}_{\mathrm{W}}=$ watcr volume, $\mathrm{cm}^{3}$

$\rho_{0} \quad=$ oil density, $\mathrm{g} / \mathrm{cm}^{3}$

$\rho_{\mathrm{w}}=$ water density, $\mathrm{g} / \mathrm{cm}^{3}$

$\Delta \mathrm{U} 1=$ weight change for $\mathrm{U} 1, \mathrm{~g}$ (compared to initial weight)

$\Delta \mathrm{U} 2=$ wcight change for $\mathrm{U} 2, \mathrm{~g}$ (compared to initial weight)

Since the total volume of U1 is constant,

$\Delta \mathrm{U} 1=\Delta \mathrm{V}_{0}\left(\rho_{0}-\rho_{\mathrm{w}}\right)$

$\Delta \mathrm{U} 2=\left(\Delta \mathrm{V}_{0}+\Delta \mathrm{V}_{\mathrm{w}}\right) \rho_{\mathrm{w}}$

From Eq. C-1 and C-2,

$$
\begin{aligned}
& \Delta \mathrm{V}_{\mathrm{O}}=\Delta \mathrm{U} 1 /\left(\rho_{\mathrm{O}}-\rho_{\mathrm{w}}\right) \\
& \Delta \mathrm{V}_{\mathrm{w}}=\left[\Delta \mathrm{U} 2 / P_{\mathrm{w}}\right] \cdot\left[\Delta \mathrm{U} 1 /\left(\rho_{\mathrm{O}}-\rho_{\mathrm{w}}\right)\right]
\end{aligned}
$$

\section{Typical Application}

For a typical unsteady-state relative permeability test, the oil and brine densitics are about $0.86 \mathrm{~g} / \mathrm{cm}^{3}$ and 1.00 $\mathrm{g} / \mathrm{cm}^{3}$ respectively, for a density difference of $0.14 \mathrm{~g} / \mathrm{cm}^{3}$. Assuming the required measurement resolution is to the nearest $0.1 \mathrm{~cm}^{3}$, the weight accuracies required for the test arc:

$$
\begin{aligned}
\Delta U 1 & =\left(0.1 \mathrm{~cm}^{3}\right)\left(-0.14 \mathrm{~g} / \mathrm{cm}^{3}\right)=-0.01 \mathrm{~g} / 0.10 \mathrm{~cm}^{3} \text { oil } \\
\Delta U 2 & =\left(0.1 \mathrm{~cm}^{3}\right)\left(1.00 \mathrm{~g} / \mathrm{cm}^{3}\right) \\
& =0.10 \mathrm{~g} / 0.10 \mathrm{~cm}^{3} \text { brine or oil }
\end{aligned}
$$

A typical plug might have the following characteristics:

$\begin{array}{lll}\mathrm{L} & = & 7.62 \mathrm{~cm} \\ \mathrm{~d} & = & 3.81 \mathrm{~cm} \\ \mathrm{~A} & = & 11.4 \mathrm{~cm} \\ \mathrm{BV} & = & 86.9 \mathrm{~cm} \\ \varnothing & = & 0.25 \\ \mathrm{PV} & = & 21.7 \mathrm{~cm}\end{array}$




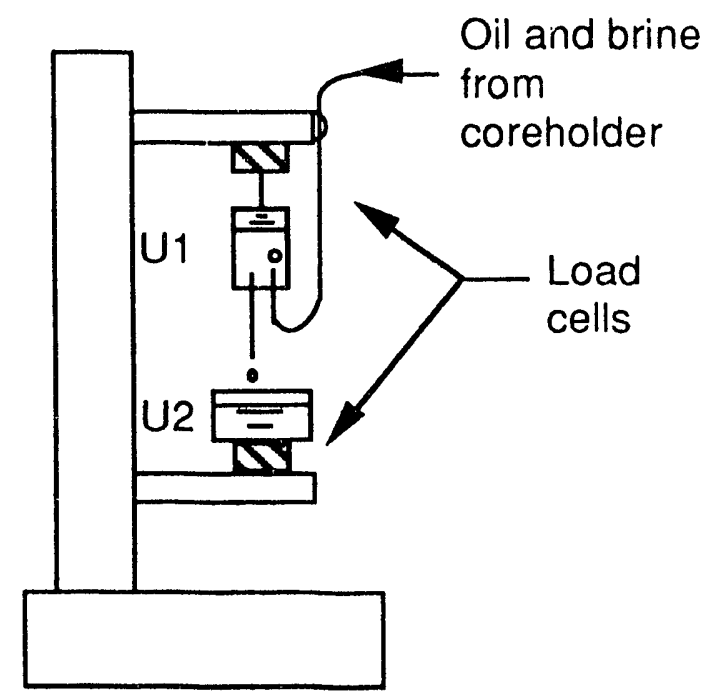

FIGURE C-1. - Proposed fixture for ineasuring unsteady-state fluid volumes.

Assuming $S_{\mathrm{Wr}}$ is 0.3 and $S_{\text {or }}$ is 0.7 , the volume of oil that would be recovered during an unstcady-state relative permeability test would bc approximatcly $9 \mathrm{~cm}^{3}$. Therefore, U1 would requirc a volume of at least $9 \mathrm{~cm}^{3}$. A $50 \mathrm{~mL}$ capacity would probably be sufficient for U1. If the U1 container weighed 30 grams and was initially filled with brine, the device used to measure U1 weight changes would require 100 gram capacity. If 20 porc volumes of fluid are injected during the test, U2 would requirc a volume capacity of approximatcly $420 \mathrm{~cm}^{3}$. The device used to measure changes in U2 weight should have 50) gram capacity.

\section{Demonstration Test for Proof of Concept}

A demonstration test was conducted to verify the method of using weight measurements to monitor lluid production. An apparatus was asscmbled in a fashion similar to that of Fig. C-1 except that two Mettler digital balances were used for the wcight measurements instead of load cells. A bottle arrangement like that shown for $\mathrm{Ul}$ in Fig. C-1 was suspended from the hook below the upper balance (Mctller PE 60) ) whilc a beaker was placed on the lower balance to capture effluent from the bottle. A syringe was used to push fluids into the botlle. The syringe was probably accurate to $\pm 0.1 \mathrm{~mL}$. For every drop of fluid that entered the bottle, a drop Icft the bottle and fell into the beaker (U2). A film of oil was placed over the fluid in the beaker to prevent cvaporation.

Two tests were conducted. The lirst test consisted of pushing brine only into the bottle, while the second test was conducted by pushing oil only into the bottle. Test results are provided in Table $\mathrm{C}-1$. The results verify that the method should work well as long as the fluid densitics are constant.

\section{Discussion}

Each unstcady-statc test takes about 1 day to perform. When volumetric measurements are manually recorded from observing the fluid volumes in graduated cylinders and other vessels, the test operator must stay with the experiment from start to finish. Water breakthrough must be observed and accurately recorded (time, volumes). The work, although very important, is tedious.

The weight method described in this report is well suited toward expcriment automation. Using electronic load cells for the weight measurements, an electronic $\Delta \mathrm{P}$ transducer, and a controllable pump, the operator can delegate the responsibility of recording all of the test data from start to finish to a computer. The computer can take more measurements, is faster, and never gets bored or tired. The computer can also calculate the final results as the test progresses. The automated system is cstimated to cost less than $\$ 4,000$ and will save about 1 man-day of work per unstcady-state test. It is casy to imagine that the system can pay for itsclf in manpower savings. An alternative scheme which might work cqually as well or better would be to use onc load cell to monitor the combined weights of $U 1$ and $U 2$ while a second load cell monitors the change in weight of U1 or U2 separately, which might yield better resolution in volumetric calculations. 
TABLE C-1. - Verification test results.

$$
\begin{aligned}
& \rho_{0}=0.8386 \mathrm{~g} / \mathrm{cm}^{3} \\
& \rho_{w}=1.078 \mathrm{~g} / \mathrm{cm}^{3} \\
& \rho_{0}-\rho_{w}=-0.2394 \mathrm{~g} / \mathrm{cm}^{3}
\end{aligned}
$$

\begin{tabular}{|c|c|c|c|c|c|c|c|}
\hline \multicolumn{2}{|c|}{ Injected volumes } & \multirow[b]{2}{*}{$\mathrm{U} \mathbf{1 , g}$} & \multirow[b]{2}{*}{ U2, g } & \multirow[b]{2}{*}{$\mathrm{U}_{1} /\left(\rho_{0} \cdot \rho_{w}\right)$} & \multirow[b]{2}{*}{$\mathrm{U}_{2} \Re_{\mathrm{w}}$} & \multicolumn{2}{|c|}{ Calculated volumes } \\
\hline $\mathbf{V w}, \mathbf{m L}$ & $V_{0}, \mathrm{ml}$ & & & & & $\Delta \mathrm{Vw}, \mathrm{ml}$ & $\Delta \mathrm{V}_{\mathrm{o}}, \mathrm{ml}$ \\
\hline 0.0 & 0.0 & 0.00 & 0.00 & 0.0 & 0.0 & 0.0 & 0.0 \\
\hline 5.0 & 0.0 & 0.00 & 5.62 & 0.0 & 5.2 & 5.2 & 0.0 \\
\hline 10.0 & 0.0 & -0.01 & 10.73 & 0.0 & 10.0 & 10.0 & 0.0 \\
\hline 15.0 & 0.0 & $-(0.01$ & 15.97 & 0.0 & 14.8 & 14.8 & 0.0 \\
\hline 20.0 & 0.0 & -0.01 & 21.42 & 0.0 & 19.9 & 19.9 & 0.0 \\
\hline 0.0 & 0.0 & 0.00 & 0.00 & 0.0 & 0.0 & 0.0 & 0.0 \\
\hline 0.0 & 5.0 & -1.19 & 5.36 & 5.0 & 5.0 & 0.0 & 5.0 \\
\hline 0.0 & 10.0 & -2.40 & 10.89 & 10.0 & 10.1 & 0.1 & 10.0 \\
\hline
\end{tabular}

*U.S.GPO: 1992-661-026/60015 


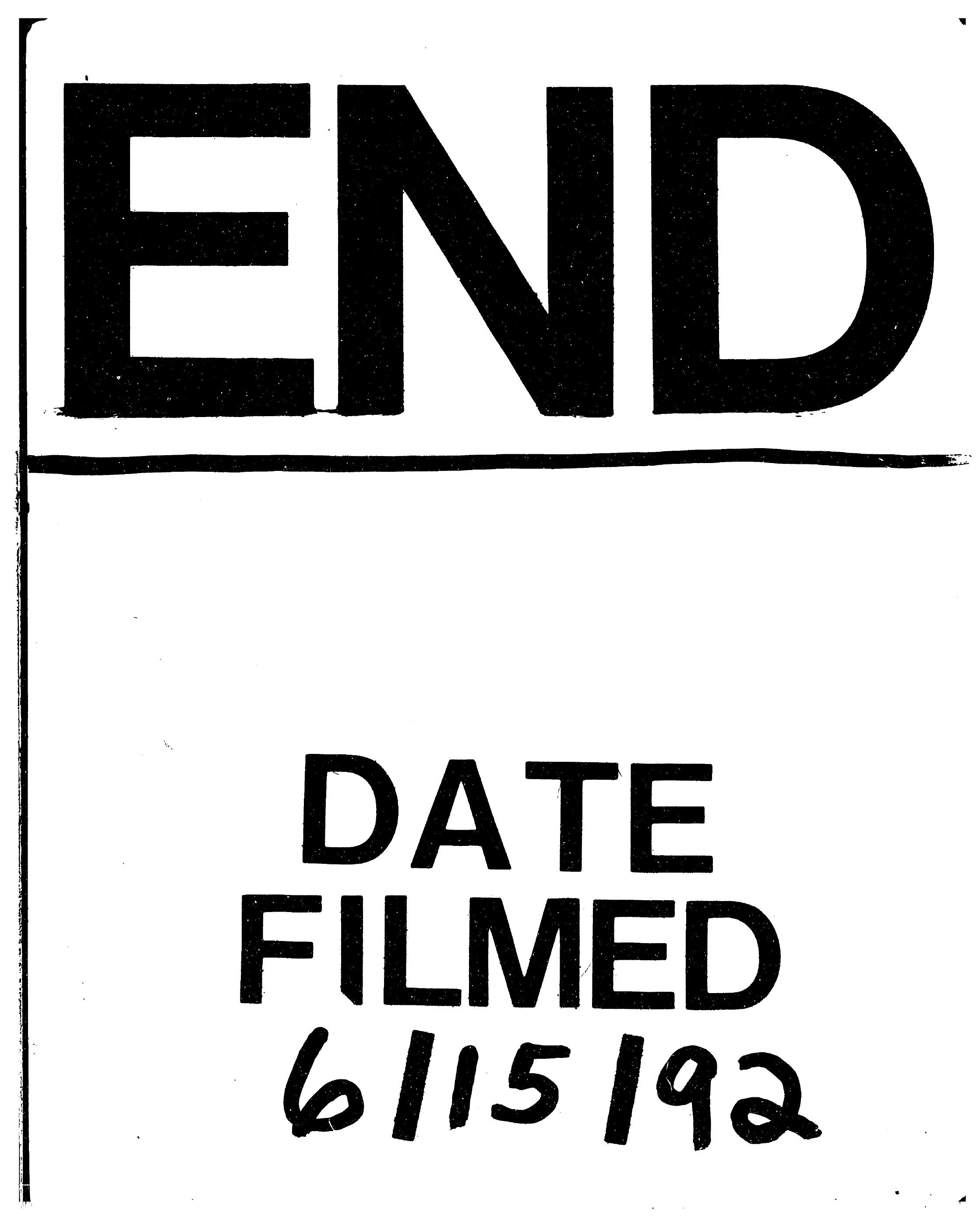




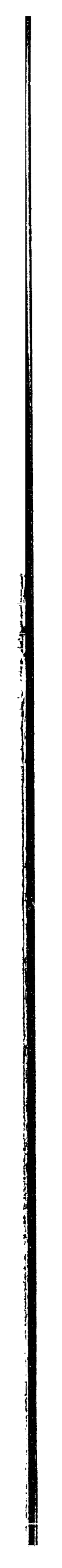

